\title{
Index for Volume 93
}

AUTHOR AND SUBJECT INDEX. Pages indicating errata are in italic. S indicates June abstract supplement. Publication number P-2003-1024-01O.

Aalsburg, J., S24

Abad, J., S1, 844, S55, S84, S99, S115

Abad, P., 160

Abad, Z. G., S1, S25

Abadias, M., 436

Abawi, G. S., S14

Abbasi, P. A., 64

Abdelshife, M. A., S76

Abdul-Baki, A. A., S14

Abi Harb, K., S2

Abies fraseri, Phytophthora root rot, in plantations, $\mathrm{S} 8$

Abo-Elyousr, K., S2

Abou-Jawdah, Y., S2

Abu-El Samen, F. M., 293

Aceria cajani, pigeonpea sterility mosaic vector, 71

Achuo, E. A., 813

Acidovorax avenae

—on cucurbits, host specificity, S88

- on watermelon, seed infestation and role of blossoms, 528

Acosta, I. F., 88

Acremonium implicatum, in Brachiaria spp., seed transmission, S43

Adachi, K., S114

Adams, K., 867

Adaskaveg, J. E., 923, S21, S127, S130

Adeoti, A. A., S3

Adhikari, T. B., 959, 1158, S2

Adipala, S5

Adkins, S., S42, S115

Afanador-Kafuri, L., 579

Agama, K. K., S2

Agarkova, I. V., S2

Agindotan, B. O., S2

Agostini, J. P., S63

Agrobacterium spp.

-A. tumefaciens: genomics, S108; hygromycin

B resistance gene transformed by, 1354; on walnut, bacteriophage for control, S22

-A. vitis, on tobacco and grape, hypersensitivity, quorum-sensing regulation, S33

Agroecosystem, organic and conventional, microbial community structure in soil, S53

Aguilar, J. M., 844

Aguilar, M., 976

Ahn, I.-P., 82

Ahonsi, M. O., S3

Ailanthus altissima, allelopathy, Fusarium as mycoherbicide, S126

Aizpún, M. T., 1553

Ajwa, H., S77

Akan, D., S51

Akimitsu, K., 768

Akinsanmi, O. A., S3

Alabouvette, C., S125

Albert, M., S48

Albugo candida, races 2 and 7, genetic and molecular analyses, 959

Alexander, B. J. R., S49, S67

Alexander, S. A., S58, S124

Alfalfa

-Fusarium crown rot, potato leafhopper injury relation, S5

-root-lesion nematode, resistance increased by oryzacystat I and II, 799

Alfano, J. R., 1274, S108, S110

Alfenas, A. C., S83

Ali, S., S3, 397
Al-Khateeb, W., S3

Allaire, M., S132

Alldredge, J. R., 805

Allen, C., S4, S30, S93

Allen, K., S114

Allen, R., S37, S88

Allium porrum, rust, inoculum density and temperature interaction, spore germination, 413

Alminaite, A., S124

Almond

- anthracnose, digital image analysis of appressoria, 923

-Colletotrichum acutatum, internal light spots, cover photo, August

-Prune dwarf virus, reverse transcription-PCR, 278

—replant disease, control, S12

-witches' broom phytoplasma, epidemic in Lebanon, S2

Alternaria spp.: on pistachio, iprodione resistance, S128; on pistachio, strobilurin resistance, point mutation, S55; on potato and tomato, different species, S27; taxonomy, restriction mapping of IGS regions, S36; toxic metabolites, in food and feed, $\mathrm{S} 99$

-A. alternata, plant-pathogen interaction, mannitol metabolism, S87

- A. brassicae, on horseradish, root-knot relation, Illinois, S6

-A. brassicicola, on crucifers, sequence analysis of ESTs in pathosystem, S62

$-A$. citri, on citrus, endopolygalacturonase gene expression, 768

$-A$. dauci, on carrot, integrated pest management, 1320

-A. mali, on apple, pyraclostrobin and boscalid effect, North Carolina, S54

-A. panax, on ginseng, protein toxin from, spore germination, 323

-A. solani: azoxystrobin sensitivity, S75; chlorothalonil sensitivity, S135

Aluminum, toxicity to plant pathogens, S26

Alvarez, A. M., 1124, S43

Alvarez, E., S4

Alves, E., S4

Aly, B., S6

Aly, R., S32

Amaranthus hybridus, stem disease and weevil infestation, S9

American Phytopathological Society

—annual meeting abstracts, S1

-annual report, 16

—author index to abstracts, S137

—distinguished service award, 23

- excellence in extension award, 25

- excellence in industry award, 26

-excellence in teaching award, 25

-fellows, 20

-forest pathology challenges and perspectives, 1056

-Hewitt award, 24

-international service award, 26

- Lee M. Hutchins award, 24

- Northeastern Division meeting abstracts, S132

- officers and committees, 14

-Pacific Division meeting abstracts, S127

-Potomac Division meeting abstracts, S123

- presidential address, funding shortage, 18

-Ruth Allen award, 23

- symposium: forest diseases and management policy, 1041; forest pathology concepts, evolution, 1052; forest pathology in North America, 20th century, 1039; forest pathology, overview, 1037; Fusarium rust in pine, disease management, 1048; Melhus student, 751; white pine blister rust, prognosis, 1044

- Syngenta award, 27

Ammar, E. D., S84

Amorim, L., 502

Amrine, J. W., Jr., S124

Anair, R. A., Jr., S132

Anchieta, A. G., S101

Andersen, P. C., S50

Anderson, J. B., S39

Anderson, J. M., 1158, 1386

Anderson, R. L., 1041

Anderson, T., S6, S62

Andrews, J. H., S60, S91, S106

Andrie, R. M., S4

Angeles, E. R., 147

Annis, S. L., S4, S70

Antonioli, R., S54

Aphanomyces cochlioides, oospore survival, solarized soils, $\mathrm{S} 90$

Appel, D. N., S102

Apple

—blue mold decay, biocontrol, S40

-Colletotrichum and Glomerella spp., species characterization, S30

—disease management, organic alternative, S8

-DNA array diagnostic system, S66

-fire blight: prediction system in Georgia, S11; resistance and rootstock effects, S40

- gray mold, biocontrol with Pichia anomala, 1145

-gray and blue mold, biocontrol, postharvest, S80

- postharvest decay: biocontrol yeasts and oxidative stress, 564; Candida saitoana for control, 344; Candida sake treatment, 436; control by heat treatment, biocontrol, and sodium bicarbonate, S50; fungus virulence factors, S105

- powdery mildew, fungicides for, S79

-scab: cultivar susceptibility and inocolum source, S41; field resistance, mapping, 493; resistance induced by chitinases, 1496

— sooty blotch, agar media, S86

- sooty blotch and flyspeck: disease-warning system in Illinois, S5; inoculation timing in Iowa, S7; postharvest removal by chemicals, S35

Arabidopsis sp.: disease resistance, polymorphism pattern, S83; nematode association, phosphoglycerate and auxin, S59; pathogen resistent gene construct, putative self-processing, S52; Pseudomonas syringae, expression profiling, accuracy, S110; RPP7 resistance pathway, molecular genetic dissection, S89

-A. thaliana: broomrape, defense gene expression analysis, 451; plant-nematode interaction, cell promoter, $\mathrm{S} 81$

Arachis hypogaea, genomics, EST technology, S55

Aranda, M. A., 844

Arcinas, A., S4

Ardales, E. Y., S94

Ariss, J. J., S5

Aritua, V., S5

Ariyo, O. A., S5 
Armentrout, D. K., S17

Armillaria spp.: North American species, sequence analysis and spacer regions 1 and 2, $\mathrm{S} 12$; on peach, using FAME profiling, S18; phylogenetic relations, ribosomal DNA sequence, S33; in red pine sites, understory, S47

-A. ostoyae, variation in western USA, S33

Arnason, J. T., 712, S97

Arnould, C., 966

Arpaia, M. L., S57

Arseniuk, E., S124

Arterburn, M., S50

Arul, J., S85

Ascochyta rabiei, on chickpea, virulence assay, S16

Ascomycete, speciation, distribution and host specialization, S98

Asensio, C., 1553

Asensio-S.-Manzanera, M. C., 1553

Ashley, R., S60

Asparagus, Fusarium crown and root rot, $\mathrm{NaCl}$ and rhizobacteria, 186

Aspergillus spp.: mycotoxin production, RNAibased control, S33; volatile metabolites, S42

-A. caelatus, vegetative compatibility group, DNA fingerprinting, S59

-A. flavus: aflatoxin biosynthesis, modulator, S24; airborne in desert, devices, S9; on cotton, Texas, S39; on peanut, trypsin inhibitor, chitinase, and beta-glucanase, S52; vegetative compatibility analysis, medium effect, S18; xylanase, purification and characterization, S60

-A. giganteus, Botrytis cinerea affected by, protein from, 1344

Assis Filho, F. M., S5, S64

Astua-Monge, G., S5, S82

Atiri, G. I., S5

Aureobasidium pullulans, on apple, phylloplane, S60

Avila, F. J., S5

Avocado, postharvest pathogens, thermal conditioning for treatment, S57

Ayoubi, P., S86

Babadoost, M., S5, S6, S39, S83, S84

Bacillus spp.: biocontrol agent, formulation, S117; biocontrol agent, IPM systems, S117; commercial application, S117; ecology in agricultural systems, S117; host defense and plant growth promotion, S117; spore assembly and function, S117; taxonomy, aerobic endospores, S117

-B. mycoides, hypersensitivity relation, independent oxidative burst, S7

Backhouse, D., S3

Backman, P. A., S6

Backus, E. A., S6

Bacon, C. W., S6, S29

Bacon, R., S6, S132

Bacteria

—biofilms, on sprout surfaces, laser microscopy, S26

-on nematodes, evolution of parasitism, S108

- potato, oligonucleotide array for identification, 262

-type III protein secretion, strategy in plant and animal hosts, $\mathrm{S} 108$

Bae, J. J., S15

Baierl, A., 657

Bailey, B. A., S10, S27

Bailey, W. D., S6

Baird, R., S68

Bakan, B., 712, S97

Baker, C. J., 1274

Bakker, P. A. H. M., 626, 813

Bakkeren, G., 167
Balaji, B., 1386

Baldini, R., S107

Ball, D. A., S129

Balogh, B., S62

Banana

—nematodes and endophytic fungi, S96

- Septoria leaf spot, in Hawaii, S130

Band, M., S51

Bandla, M., S9, S34, S57

Bandyopadhyay, R., S65

Banerjee, M. K., 1485

Banko, T. J., S123

Bao, J., S27

Barak, J. D., 596

Barakat, M., 1505

Baraoidan, M., S57

Barasubiye, T., S6

Barbara, D. J., 364

Barbetti, M. J., 1073

Bar-Eyal, M.,127

Barg, E., S5

Bargabus, R. L., S7

Barley

-bymoviruses, recent in Korea, S38

- diseases and direct seeding, S77

-leaf rust, molecular mapping of resistance gene, 604

-powdery mildew: acibenzolar-S-methyl and ethirimol effect on, 305; disease resistance signal, S32; durable resistance and the mlo gene, $\mathrm{S} 112$

-soilborne pathogens, survey in Idaho, S81

Barley stripe mosaic virus, nucleotide substitutions, S75

Barley yellow dwarf virus

- on cereals, yield loss prediction, aphid abundance, 1217

- cereal yellow dwarf virus comparison, detection tests and vectors, S9

-quantification with PCR, 1386

Barley yellow mosaic virus, linkage analysis, resistance screening, in Korea, S38

Barnes, C. W., S82

Barnes, S. E., 573

Barnett, M. J., S108

Baron, J. J., S11

Barrera, O., S6

Barreto, D., S71

Barrett, T. L., S7

Bartels, D., S84

Barthe, G. A., S20

Bartz, J. A., S56

Bassanezi, R. B., 502

Bastien, C., 421

Battilani, P., S99

Batzer, J. C., S7, S35, S86

Bau, H.-J., 112

Baudoin, A., S7, S124

Baum, T. J., S21, S23, S28, S53 S59, S88, S91

Bausher, M., S55

Bayles, M. B., S7

Bean (see also Phaseolus spp.)

- disease resistance genes, deployment, S70

— viruses, spatial pattern in New York, S78

Bean common mosaic necrosis virus

-Host Group 3, NL-3 K strain, 683, S81

-resistance screening method, 1430

Bean common mosaic virus, Bean common mosaic necrosis virus, recombination event, $\mathrm{S} 48$

Bean pod mottle virus

—foliar insecticide timing, S95

-reassortant isolate, interstrain recombinant, S94

-on soybean: early and late inoculation comparison, S73; hilum bleeding symptom, S68; seed coat mottling, S56
Bean and sugar beet, wheat as alternate hosts for pathogens, in Nebraska, S34

Beanland, L., S7

Beasley, J. P., S10

Beattie, G. A., S106

Beaver, J., S75

Becerra, V. V., S56

Becker, J. O., 1006, S67, S128, S129

Becktell, M. C., S7

Bedford, K. E., S66

Beebe, S., 88

Beet curly top virus, on chile pepper and weeds, in New Mexico, S37

Beet mild curly top virus, movement rate in beet leafhopper, 478

Beet necrotic yellow vein virus

- pathotypes in California, S54

- on sugar beet, remote detection, 720

Beet pseudoyellows virus, on strawberry, new, $\mathrm{S} 85$

Begomoviruses

-bipartite, genome size and DNA movement, S109

-detection in plant extracts, comparison of techniques, 1153

- diversification in world, mechanisms, S101

-field populations in Pakistan, Bemisia tabaci genetics, 1422

- gene silencing and host factors, S109

-host-whitefly co-evolution, S99

-interactions between, S109

Beitia, F., 1422

Bélanger, R. R., 402, 535, S74, S132, S133

Belfon, R., S7

Bell, A. A., S7

Belmar-Díaz, C., S25

Belonolaimus longicaudatus, embryogenesis, thermal time, $\mathrm{S} 128$

Bemisia tabaci, begomovirus vector, genetics, Pakistan, 1422

Bender, C. L., S86

Bengough, A. G., 1111

Benhamou, N., 402, 535, 1308, S74

Bennett, M. A., S91

Ben-Noon, E., 1320

Benson, D. M., 1115, S8, S26, S38, S118

Bent, A. F., S110

Bentley, T. C., S112

Berbee, M. L., S98

Beretta, M. J., S20

Berg, M., 1233

Bergamin Filho, A., 502

Bergdahl, D. R., S133, S134, S135

Bergelson, J., S83

Berger, P. H., S2, S24, S52, S78

Bergfeld, S., S130

Bergstrom, G. C., 1131, S13, S77

Berkett, L., S8

Berland, P. A., S8

Berner, D. K., S3, S10

Bernier, L., S41, S132, S134, S135, S136

Berry, S. A., S73

Bertagnolli, P. F., S103

Bertolini, E. 286

Bertrand, P., S58

Besler, B. A., S60

Best, V. M., S87

Betula papyrifera, ectomycorrhizae, soil type and management effect, S48

Beveridge, T., S79

Bextine, B. R., S8

Beyl, C. A., S68

Bhat, R. G., S8, S127, S131

Bhattacharyya, M. K., S40

Biggs, A. R., S20

Bilodeau, G., S8 
Bily, A. C., S97, 712

Biodiversity

-agricultural systems, general and specific, S100

—plant pathogens, obstacles and opportunities, S100

Biological control

-apple gray mold, yeast, 1145

- bacteria in wheat rhizosphere, strain interactions, 982

-Botrytis and Penicillium on stored apples, resistance, 564

- Candida saitoana for apple fruit decay, postharvest, 344

- Candida sake for apple postharvest diseases, 436

-Clonostachys rosea for pea root rot complex, 329

- composted potting mix for Rhizoctonia solani on impatiens, 1115

-GFP reporter genes for study, S104

- Lysobacter enzymogenes for Bipolaris sorokiniana on tall fescue, 1103

-nematode-trapping fungi and correlation with most probable number, 1599

_ production and delivery of agent, assay, S79

- Pseudomonas fluorescens for pear fire blight, 727

-Pseudomonas putida for Fusarium wilt of radish, 626

-Pseudomonas spp. for take-all decline in wheat, 54

-rhizobacteria for Cucumber mosaic virus on tomato, 1301

—risk assessment, ecological approach, S104

-soilborne pathogens, vegetables and wheat, S125

Biopesticide, risk assessment, monitoring agents, S45

Biosca, E. G., 485

Biotechnology

-biosafety issues, Africa, S111

- disease control in developing countries, S110

-intellectual property issues, developing countries, S111

Bioterrorism

—agricultural systems, genetic/molecular modification, S100

-detection on plant surfaces, QPCR and TRFLP, S71

- pathogen spread, S100

-wild cereal species, genetic diversity, S100

Bird, D. M., S108

Bird, J., 774

Bisaro, V., 136

Biswas, K. K., S8

Black, M. C., 1368

Blackberry, chlorotic line pattern, crinivirus association, S85

Blanchette, R. A., S47

Blanco-Labra, A., 917

Blee, K. A., S10

Blein, J.-P., 1308

Bliss, W. O., S9

Blodgett, A. B., S50

Blodgett, J. T., S9

Blueberry

- cultural practice and disease, in Maine, S4

- Godronia canker, S35

-mummy disease, leaf bud phenology, S70

-resistance genes, degenerate primers, S72

Bluhm, B. H., S9

Blum, K., S9

Blumeria graminis

- on barley, acibenzolar-S-methyl and ethirimol effect, 305 -on wheat, silicon effect on resistance, cytology, 402

Blunt, T. D., S127

Boal, R. J., S92

Bobrova, V. K., S9

Bock, C. H., S9, S10, S70, S88

Bockus, W. W., S4

Boehm, M. J., S17, S41, S83, S94

Boer, Y., 1360

Boland, G. J., 1407, S14

Bom, P., 626

Bonde, M. R., S10, S102

Bonello, P., S9, S48, S55

Bonman, J. M., S113

Boosalis, M. G., S26

Boozer, R. T., S76

Borja, M., 1344

Borneman, J., 1006, S67

Bosselut, N., 160

Bostock, R. M., S121

Botryosphaeria dothidea, on pistachio, spatiotemporal genetic structure, in California, S128

Botrytis spp.

-B. cinerea: Aspergillus giganteus protein effect on, 1344; disinfestants, dose curves, S17; on grape, defense reaction and latency, 316; on grape, resistance correlations, 1263; on pomegranate, fungicide management, $\mathrm{S} 127$; on primula, latent disease spread, 573; on raspberry, fungicides, S127

-B. fabae, on bean, phytoalexin and peroxidase activity, S48

Bottalico, A., S98

Bottner, K. D., 1368, S49

Bouchara, J.-P., 1023

Boudon-Padieu, E., 1308

Boudreau, M. A., S10

Boul, R. B., S10

Boulanger, R., S85

Boule, J., S79

Boulé, N. A., S132

Bourassa, M., S132

Bousset, L., 305

Bouterige, S., 1023

Bové, J. M., 502

Bowden, R. L., 874, S18, S19

Bowen, K. L., S10, S64

Bowers, J. H., S10, S20

Bowers, T. A., S10

Boyhan, G. E., S77

Bozarth, R. F., S63

Bradley, C. A., S10, S81

Bradshaw, T. L., S8

Brain, P., 657

Brandl, M. T., S105

Brannen, P. M., S11, S25

Brantner, J. R., S90

Brasier, C. M., S98, S106

Brassica spp., black spot, model pathosystem, $\mathrm{S} 18$

-B. juncea, soilborne pathogens inhibited by,

$\mathrm{S} 11$

-B. napus, light leaf spot, epidemic in United Kingdom, spatial aspects, 657

Braun, P. G., S11

Braverman, M. P., S11

Bredehoeft, M., S81

Breeden, T. S., S11

Brenneman, T. B., S11, S44, S123, S125

Brenneria quercina

-on Quercus ilex, cankers, cover photo, April

—on Quercus spp., characterization in Spain, 485

Breuil, C., S134

Brevipalpus sp., rhabdo-like virus transmitted by, diagnosis, S54

Brewer, M. T., S11
Brey, C. W., S103

Bristow, P. R., S127

Britton, K. O., S34

Brlansky, R., S19, S30, S57, S63, S75

Brodhagen, M., S11, S72

Bronson, J. J., S12

Brooks, R. A., S71

Brouwer, M., S52

Brown, D., S12, S22, S30, S83

Brown, J. E., S81

Brown, J. K., 774, S38, S99, S101

Brown, K. M., S45

Brown, L. G., S12, S41

Brown, M. R., S10

Brown, R. L., S12

Brown, S. E., S39

Brown, S. L., S115

Brown, W. M., S127, S130

Browne, G. T., S8, S12, S77

Brown-Guedira, G. L., 784

Browning, H. W., S101

Browning, M., S12

Brucella sp., comparative and functional genomics, plant and animal similarity, S107

Bruck, R. I., S10

Bruckart, W. L., III, S123

Bruton, B. D., 1233, 1240, S90, S94

Bryan, G. T., 1452

Bryson, P. K., S12

Buchenauer, H., S90

Bucholtz, D. B., 1386

Buck, C., S31

Buck, J. W., S63, S118

Budding, D. J., 666

Buell, C. R., S108

Buell, R., S110

Bukhalid, R. A., S44

Bull, C. T., S12, S29

Bulluck, L. R., III, S130

Bulluck, R., S41

Burbidge, J., S67

Burdsall, H. H., Jr., S119

Burke-Scoll, K., S76

Burkholderia cepacia

-on onion, populations, organic soil and other crops, S34

-in organic soil, populations and pathogenicity, S133

Burmester, C., S38

Burr, J. A., S90, S91

Burr, T. J., S33

Burrows, P. M., 127

Bursaphelenchus xylophilus, on pine, abamectin treatment, S39

Burt, A. J., 712

Busboom, K. N., S13

Butternut

- canker, conidiospores on beetle vectors, S135

- curculios, wounds, S133

Butterworth, S. C., S76

Buyer, J. S., S14, S125

Byrd, G., S12

Cabbage, leaf curl, mixed infection with virus, Jamaica, S75

Cadena-Hinojosa, M., S25

Cadet, P., 1437

Cadle-Davidson, L., 1137, S13

Cadle-Davidson, M., S13

Caemorhabditix elegans, bacterial artificial chromosome libraries, S59

Cai, G., 1014, S13

Cajanus cajan, sterility mosaic disease, mite transmission, 71

Caldwell, W. D., S104

Callahan, A. M., 349 
Callahan, S. D., S74

Calla lily, methyl bromide for, alternative treatment, S29

Cambra, M., 286

Cameron, K. D., S13, S44

Cammue, B. P. A., S52

Campaña, A., S13

Campbell, K. W., S46

Campbell, L. H., S32

Candida spp.

-C. saitoana, apple fruit decay controlled by, postharvest, 344

-C. sake, biocontrol agent, apple postharvest, 436

Candidatus Phlomobacter fragariae, planthopper vector, 644

Candole, B. L., S13

Canola, blackleg sporacle, model for predicting ascospore showers, 1073

Cantoral, J. M., S14

Capsicum annuum

- anthracnose, calcium/calmodulin-dependent signaling, prepenetration, 82

-thrip resistance, Tomato spotted wilt virus spread restriction, 1223

-Tomato spotted wilt virus, thrips resistance, 96

-Xanthomonas campestris, race 3 , bacteriocinlike substances, 1415

Caputo, L., 564

Carbu, M., S14

Cardwell, K. F., S116

Carisse, O., S6, S14, S41, S132

Carlson, R. W., S34

Carpenter, J., S14, S37

Carpenter-Boggs, L., S89

Carrera, L. M., S14

Carriquiry, A. L., 758

Carris, L., S73, S89

Carroll, J. E., 1137, S14

Carrot

-Alternaria leaf blight, integrated pest management, 1320

—cavity spot, Pythium spp. in Quebec, S132

- foliar blight, fungicide and disease forecaster, $\mathrm{S} 22$

-leaf blight, IPM management program, in New York, S14

- pesticides for, production system, S74

Carta, L. K., S2, S61

Carter, E. A., S35

Cartinbour, S., S110

Cartwright, R., S3, S40

Caruso, F. L., S14

Carvalho, S. A., S5

Cassava

-bacterial blight, marker detection in Colombia, S4

-mosaic: biotechnology in tropical agriculture, S110; screening genotypes, S5

- phytoplasm-frogskin disease, detection, S4

Castagnone, C., 160

Castillo, P., 1093, 1513

Castoria, R., 564

Castro, A. C., 528, S60, S88

Catal, M. C., S76

Catharanthus roseus

-Phytophthora blight, phosphite foliar sprays, S123

-vinca virescence, gene expression, S84

Catlin, N. J., S14

Cavin, C. A., S123

Celetti, M. J., S14

Cenis, J. L., 1422

Cephalosporium spp.

- C. gramineum, on wheat, detection with PCR, S87
-C. maydis, diversity and amplified fragment length polymorphism, Egypt, 853

Ceratocystis spp.

-C. fimbriata: host specialization, in Brazil, S83; Latin American clade, variability and host specialization, 1274

-C. resinifera, genetic variability, Canadian population, S134

Cercospora spp., on sugar beet, leafspot prediction model, S44

-C. arahidicola, on peanut, pyraclostrobin effect on germination, $\mathrm{S} 54$

-C. beticola, on sugar beet, conidial dispersal, $\mathrm{S} 44$

-C. kikuchii, vegetative compatibility groups, $\mathrm{S} 13$

-C. zeae-maydis: on maize, cercosporin and pathogenesis, kinase homolog, S78; microcycle conidiation, 193 stromata, increase on corn residue, $\mathrm{S} 26$

Cereal yellow dwarf virus, quantification with PCR, 1386

Ceresini, P. C., 610, S25

Ceri, H., S57

Cha, B. J., S42

Chabane, K., S92

Chaetocnema pulicaria, on corn, Stewart's disease vector, beetle infections, 210

Chakraborty, S., 176, 1485, S3

Chalara elegans, mitovirus in, molecular characterization, S69

Chan, Y.-K., S15

Chancey, S. T., S108

Chandok, M. R., S15

Chandrika, R., S15, S57, S86

Chang, C. J., S76

Chang, T. H., S15

Charchar, M. J. d'A., 176

Charkowski, A. O., S67, S93

Charudattan, R., S15, S63, S75, S92

Chase, T. E., S15, S94

Chastagner, G. A., S128

Chatterjee, A. K., S110

Chen, C. S., S15

Chen, H., S16, S83

Chen, J., S16

Chen, K. C., S15

Chen, P., S14, S95

Chen, S. (Nebraska), S105

Chen, S. Y. (Minnesota), S16, S123

Chen, W., S16

Chen, X. M., S16, S42

Chen, Y. C., S15

Chen, Z.-Y., S12

Chenault, K. D., S16

Cheng, Y.-H., 112

Cheng, Z.-M., S88

Chevalier, M., 1496

Chevreau, E., 1496

Choi, J. J., S16, S46, S55, S108

Choueiri, E., S2

Christ, B. J., S135

Christianson, T., S65

Chun, W. C., S73

Chung, K. R., S17

Ciampi, M. B., S25

Cianzio, S. R., S66

Cicer arietinum, Fusarium and root-knot interactions, 1513

Ciomperlik, M., S84

Circulifer tenellus, Beet mild curly top virus vector, virus movement in vector, 478

Citovsky, V., S109

Citrus

-Alternaria black rot, postharvest fruit disease, endopolygalacturonase gene expression, 768 -canker: detection in field, S59; detection at port facilities, S76; disease in tissues, 832; genetically engineered resistance, $\mathrm{S} 15$; law and science conflicts, S121; science/legal conflicts, S120; wind dispersal of bacteria, S9

- exotic pathogens, Florida, S101

- greasy spot, ascospore release and dispersal factors, 1031

—postbloom fruit drop, fungicides, Brazil, S70

- postharvest decay, thiabendazole and sodium bicarbonate, $\mathrm{S} 105$

- postharvest disease control: azoxystrobin, S17; fludioxonil, S17, S94

- sudden death: haplotypes, gene analysis, S82; spatial and temporal analyses and etiology, 502

-Xylella fastidiosa, geographic genetic structure, Brazil, 28

Citrus leprosis virus, in Panama, characterization, S30

Citrus psorosis virus, natural spread in Texas, S61

Citrus tristeza virus

—antibody development, S86

-aphids and genetic diversity, evolution, S99

-in citrus roots, sudden death relation, S20

- genotypes, India, S75

—new genotypes, heteroduplex mobility assay, S57

- population diversity, strains for cross-protection, S8

- primers for cloning of genome, S35

-in transgenic grapefruit, pokeweed antiviral protein, $\mathrm{S} 71$

Ciuffetti, L. M., S4

Ciufo, S., S134

Civerolo, E., S16, S84

Cladosporium carpophilum: on peach, conidial production, seasonal, S76; on peach, moisture sources, conidial dissemination and infection, 1581

Claeys, D., S20

Clarke, B. B., S18, S29, S112

Clarke, C. T., S41

Clavibacter michiganensis

_biofilm evaluation, S57

_-genome sequencing project, S39

- on tomato seed, survival, S43

Claviceps purpurea, host range in California coasts, S26

Clayton, M. K., 1082

Cleere, S., S67

Cleveland, T. E., S12

Clifford, J. M., S133

Climatology, disease occurrence and geographical patterns, S51

Clonostachys rosea, pea root rot controlled by, 329

Clough, S. J., S17

Cloutier, J.-S., S133

Coakley, S. M., 751

Cobb, B., S120

Cober, E., S6

Cochran, A., S17

Coconut, lethal yellowing phytoplasma, carbohydrate metabolism, 976

Coffee, wilt, in Uganda, S50

Coffman, V. A., S30

Cohen, S. D., S119

Cohn, D. R., S123

Colburn, G. C., S17

Cole, C., S17

Cole, F. M., 316

Coletta-Filho, H. D., 28

Colletotrichum spp.: on mango, survey in Puerto Rico and Florida, S74; on Russian thistle, biocontrol in Hungary, S123; on strawberry, 
genetic diversity and pathogen variability, 219; on tamarillo, passiflora, and mango, isolate characterization in Colombia, 579

-C. acutatum: on almond, appressoria, digital image analysis, 923; on almond, infection process, S21; on blueberry, infection, S90; on citrus, indole derivatives, S17; endo-polygalacturonases, cloning, S69; on highbush blueberry, dormant infection, S20; on strawberry, fungicide dip treatments, S34; on strawberry, fungicides and latent colonization, S61; on strawberry, plant extract effect on conidia, 1285; on strawberry, temperature and wetness duration effect, conidia and appressoria, 513

-C. coccodes, vegetative compatibility groups, on potato in North America, S66

-C. gloeosporioides: pectate lyase secretion, factors, S105; on pepper, calcium/calmodulindependent signaling, prepenetration, 82; on Stylosanthes spp., genetic diversity and centers of origin, 176

-C. graminicola: biology and genetics, S111; spore dimorphism, S87; on turfgrass, fungicide resistance, biology, S18; on turfgrass, pathogenicity and host specificity, S112; on turfgrass, thiophanate-methyl, resistance, California, S91; on turfgrass, transposon fingerprint profiles, S29; on turfgrass, vegetative compatibility, intron sequence analysis, S112

-C. sublineolum, on sorghum, temporal and spatial development, S52

Collins, A. (U.K.), 364

Collins, A. A. (Delaware), S17

Collins, D. J., S17, S81

Collmer, A., S108, S110

Colon, L. T., 666

Colowit, P. M., S8

Colyer, P. D., S104

Coniothyrium minitans, biocontrol of Sclerotinia blight on peanut, S70

Connell, J. H., S12

Converse, R. H., 380

Conway, W. S., S50, S69, S105

Cook, M. J., S77

Cooke, D. E. L., S98

Cooke, P. H., S26

Coops, N., 1524

Copes, W. E., S17

Coplin, D. L., S32, S61

Core, A. B., S17

Corn (see also Maize)

-Aspergillus ear rot, resistance source, S13

- fumonisin in grain, seed treatment, S46

-Fusarium ear rot and fumonisin, hybrid evaluation, S46

- gray leaf spot, microcycle conidiation of Cercospora zeae-maydis, 193

- hydrophobic amylase inhibitor, active against Fusarium, 917

-root-knot nematode, root border cell presence, activity, 1111

—silage, mycotoxins, S97, S98

- stalk rot, insects and diseases of, treatment evaluation, S46

-Stewart's disease: flea beetle populations, 210; vector control, S61

- sweet, high plains disease, seed transmission, S127

Cornelissen, B. J. C., 1360

Cornus spp. (see also Dogwood)

-C. florida, powdery mildew, resistance and PR10 protein, $\mathrm{S} 5$

-C. mas, bacterial blight, control, S66

Correa-Victoria, F. J., S18, S54

Correll, J. C., S30, S87, S112

Costamilan, L. M., S103
Cotterill, P. J., 752

Cotton

—aldicarb breakdown, in Alabama, S38

-bacterial blight resistance, near-isogenic lines, $\mathrm{S} 7$

-bronze wilt, environment protocol, S7

- commercial seed, aflatoxin contamination in Texas, 1190

-damping-off, biocontrol using pathogen germination inducers, S37

-nematodes, messenger, EBC-583, and plant growth, S46

-reniform nematode, site specific management, S48

-transgenic cultivars, root-knot reproduction and severity, $\mathrm{S} 104$

-Xanthomonas campestris, phyllosphere inoculation technique, 1204

Cotty, P. J., 1190, S9, S18, S39, S60

Counce, P. A., S49, S79

Cousin, M. A., S9

Cover photo

-almond, Colletotrichum acutatum, internal light spots, August

-Brenneria quercina, on Quercus ilex, cankers, April

-Cucurbit yellow stunting disorder virus, in Cucumis melo, RNA detection, July

-maize, trichome, microcycle conidiation, February

-Meloidogyne artiellia, on chickpea roots, December

-Meloidogyne incognita, on maize root, September

-Monilinia fructicola, on canned peaches, November

-Papaya ringspot virus, resistance to geographic strains, January

-rice: Magnaporthe grisea on, mesophyll cell, May; sheath blight, stem lesions, March

-Xanthomonas campestris, on cotton leaves, October

-Xylella fastidiosa, fimbriae produced by, June

Covert, S. F., S41, S134

Cox, C. M., S18

Cox, K. D., S18

Coyne, C., S16

Cram, M. M., S18

Cramer, C., S32

Cramer, R., S18, S62

Cranberry, stem galls, bacterial isolations, S87

Crane, B. R., S44

Craven, K. D., S18, S62

Creamer, R., S7, S37

Crinipellis perniciosa, on cacao, genetic diversity, S71

Crisosto, C. H., S69

Cronartium spp.

-C. quercuum, on pines, genetic diversity, S134

-C. ribicola: multiple hosts, genetic structure, S73; speciation mechanism, gene flow, S98; on white pine, resistance gene $\mathrm{Cr} 2$, distribution, 691

Crouch, J., S18, S29

Crow, W. T., S19, S36

Crowe, F., S67

Crowley, M., S129

Crucifer

—Verticillium wilt, molecular types, 364

-white rust, genetic analysis of races 2 and 7 , 959

Cryphonectria parasitica

- chestnut, deletion of hypoviral-regulated gene, S45

-cryparin in, processing and secretion, S85

-ERK homologue, cloning, S42
-HOG1 homologue, cloning, S69

-reovirus isolated from, Coltivirus relation, S36

-replication cycle and secretory pathway, components, S85

Cryptococcus nodaensis, freeze-drying survival,

$\mathrm{C} / \mathrm{N}$ ratio, $\mathrm{S} 94$

Csinos, A., S19, S20, S58

Cubeta, M. A., 610, S1

Cucumber, Pythium root rot, biocontrol, S45

Cucumber mosaic virus

—on cowpea, resistance marker, S29

- synergy with Pepper mottle virus, in bell pepper, S64

-on Tetragonia expansa, systemic infection and temperature, 1445

-on tomato, rhizobacterium-mediated growth promotion, protection, 1301

Cucumber mosaic virus, variation and population dynamics, transgenic plants, S100

Cucurbit

- disease management, famoxadone-based fungicides, S58

— viruses, distribution in Florida, S89

-yellow vine disease: genotyping strains, techniques, 1240; strains and phylogenetic analysis, 1233

Cucurbit yellow stunting disorder virus, on $\mathrm{Cu}$ cumis melo, RNA detection, cover photo, July

Culbreath, A. K., S115, S125

Culler, M. D., S19

Culvenor, D., 1524

Cumagun, C. J. R., S19

Cunfer, B. M., S10

Curcurbit yellow stunting disorder virus, on melon, virus accumulation, 844

Curtis, V. L., S70

Cuzick, A., S89

Cycas necrotic stunt virus, on ornamentals, detection in New Zealand, S67

Cylindrocarpon destructans

-on ginseng, detection, 1533

- on grape, composted soil amendments, S31

Cynodon dactylon, dematiaceous hyphomycetes on, resistance detection and inoculation technique, 1565

Czembor, P. C., S124

Daayf, F., S94

Dactylaria higginsii

-bioherbicidal fungus, IPM component, tomato, S75

-bioherbicide for purple nutsedge, pesticide effect, S92

-nutsedge in pepper suppressed by, surfactants, S63

Dagraca, J. V., S61

Dahlia, viral diseases of, management, S69

Dai, Q., 1354

Dai, W., S88

Dakhil, H., S2

Dallot, S., 1543, S19

Dally, E. L., S95

Damicone, J., S114

Damsteegt, V. D., S19, S25, S100

Dane, R. A., 1368

Danet, J.-L., 644

Dang, P., S55

Dardick, C., 705

Darsow, J., S129

da Silva, F. G., 705

Database, plant pathogen, genetic and phenotypic information, resource, S43

Datnoff, L. E., 256, 535, S74, S81

Daub, M. E., S35, S82, S87

Daughtrey, M. L., S7, S118, S122, S125, S135

Davelos, A. L., S106 
Davidson, J. M., S28

Davies, R. J., S35

Davis, E., S21, S23, S28, S37, S59, S81, S88, S91

Davis, M., S74

Davis, R. E., S95, S124

Davis, R. F., S82

Davis, R. M., 1014, S24, S45

de Boer, M., 626

De Boer, S. H., S57, S92, 262

Dean, R. A., S12, S21, S22, S40, S42, S47, S82, S83

Dean, R. E., S29

Debode, J., S20

de Boer, M., 626

De Boer, S. H., S57, S92, 262

Decanini, L., S39

De Ceuster, T. J. J., 1292

De Cicco, V., 564

De Cock, A. W. A. M., S8

De Curtis, F., 564

De Dobbelaere, I., S19

Dedryver, C. A., 1217

Defago, G., S3

Dehaan, T. L., S92

De Jonghe, K., S19

De La Fuente, L., S20

Delaney, T. P., S110

Delavault, P., 451

Délye, C., 219

DeMarsay, A., S20

Deng, F., 1407

Denoyes-Rothan, B., 219

Denslow, S. A., S35

de Oliveira, M. C., S16

Deom, C. M., S5, S64

Derie, M. L., S22

Derksen, R. C., S118

Derr, J. F., S125

Derrick, K. S., S20

Desaeger, J., S20

Desbiez, C., 1478

de Silva, A., 1124

de Souza, J. T., 54, 966, S20

Desvoyes, B., S95

Detter, J. C., 675

Detwiler, E. A., S40

Deulvot, C., 966

DeValerio, J. T., S15, S63, S75

Dewdney, M. M., S20

De Wolf, E. D., 428, S20, S53, S133

Déziel, E., S107

Dezwaan, T., S114

Diab, H. G., 1115, S21, S26

Diagne, M., S21

Diagnostics

- data analysis, event detection, S121

-National Plant Diagnostics Network, bioterrorism and sustainability, S121

-response activation and decision support mechanisms, S121

—standard practices, requirements, $\mathrm{S} 121$

Diaporthe spp.

-D. citri, pycnidial development factors, $\mathrm{S} 63$

$-D$. phaseolorum, on soybean, variability in Argentina, molecular characterization, 136

Díaz-Valasis, M., S25

Dick, R. P., S67

Dicklow, B., S135

Dickman, M. B., S100, S105

Dickstein, E. R., S66

Didymella bryoniae, on plants and in air, detection, S86

Diéguez-Uribeondo, J., 923, S21

Diener, S. E., S21

Diggle, A. J., 1073
Dillard, H. R., S78

Dill-Macky, R., S19, S75

Dinesh-Kumar, S. P., S110

Ding, S. W., S107

Dinoor, A., 1320

Disease forecasting

- MARYGLYT and Cougarblight, for fire blight on apple and pear, S20

-models, Fusarium head blight of wheat, factors, $\mathrm{S} 20$

Disease management

- greenhouse crops, electrolyzed oxidation water, S118

—organic crops, Australia, S134

—ornamental plants, principles, S122

— pear fire blight, warning system in Israel, 356

-resistance induced in greenhouse crops, S118

-root-knot nematode, cucumbers and squash, double cropping, S 82

- storage and analysis system, Alkahest NuclearBLAST, S21

Ditylenchus dipsaci, on onion, chemo attractant, 127

Dively, G. P., S21

Di Vito, M., 1513

Dixon, A. G. O., S5

Dixon, E. W., 891

Dixon, P. M., 513, 1285, S7, S35

Djonovic, S., S21

Dobinson, K. F., 1533

Dobrowolski, M. P., 695

Dodd, K. K., 1082

Dogwood (see also Cornus spp.)

- powdery mildew, spray program in disease management, S62

Donahoo, R. S., S21

Dong, R., S37

Dongyi, H., S43

Donofrio, N., S22

Dopkins, D. M., S33

Dorman, C., S6

Dorman, E. A., S22

Dorrance, A. E., S73, S87

Dos Santos, A. R., S85

Dothistroma septospora, on Pinus radiata, hyperspectral imagery for assessment, 1524

Douglas-fir, Swiss needle cast

—quantification methods, 121

—severity, prediction in Oregon, 790

Douhan, G. W., 650

Doukhanina, E., S105

Dowkiw, A., 421

Driks, A., S117

Driver, J. G., S22

Drori, N., S105

Druffel, K., S48, S69

Dry, I. B., 547

Dudzinski, M., 1524

Dufault, N. S., S133

Duffie, L. E., S10

Dugan, F. M., S100

Duncan, J. M., S98

Duncan, K. E., S22

Duniway, J. M., 443, S33

Dunkle, L. D., 193, S33, S78

Dunning, F. M., S110

Dupper, G. E., 691

Dupuis, F., 1496

Dute, R. R., S34

Du Toit, L. J., S22

Dwinell, L. D., S27

Dyer, A. T., S90

Dyer, P. S., 650

Easley, S. A., S79

Eayre, C. G., S22
EcoPort Web site, plant pathology resource, S49

Edmunds, B. A., S22, S23, S46

Edwards, M. C., S75

Edwards, S. G., 364

Effertz, R. J., 604

Eisenmann, J. A., S23

Eizenga, G. C., S40

El-Allaf, S. M., S23

El-Assiuty, E. M., 853

Eleocharis kuroguwai, mycoherbicide efficacy, S37

El Ghaouth, A., 344, 349

Elias, E., S3

Elias, K. S., 1014

Elling, A. A., S23, S59

Elliott, D. R., S49, S67

Elliott, M. S., S15

Elliott, P. E., S23

Ellis, C. E., S11

Ellis, M. A., 995, S65

Elm, Dutch elm disease, monitoring spread, S106

El-Mehtar, S., S2

Elmer, W. H., 186, S23, S64, S133

Elmore, C. L., S29

Embellisia sp., on locoweed, endophytic, analysis, $\mathrm{S} 7$

Emechebe, A. M., S3

Endres, G., S10, S60

England, R., S24

Englander, L., S12

English, J. T., S54

English-Loeb, G. M., S60

Enterobacter cloacae, Fusarium dry rot affected by, in stored potato, factors, S86

Epichlö̈, life cycle, evolutionary process, S98

Epicoccosorus nematosporus, mycoherbicide for Eleocharis kuroguwai, S36

Eriksen, W., S45

Ertürk, Ü., S17

Erwinia spp.: infectivity of injured cells, S52; on pear, genetics in Japan, 1393

-E. amylovora: on apple, survival on shoots, $\mathrm{S} 66$; induced resistance to, bioagents, $\mathrm{S} 2$; on pear, diagnostic medium and sampling procedure, 931; plant extracts, control by, S2; in Rosaceae family, factors, S11

-E. carotovora: biofilms, antibiotic susceptibility, S57; genomics and pathogenicity, S93

Erysiphe necator, PCR for detection, S24

Eskalen, A., S24, S129

Esker, P. D., 210, S24, S61

Esmenjaud, D., 160

Espadas, F., 976

Espinosa, A., S108

Essenberg, M., 1204, S7

Eutypa spp., on grape, new species in California, $\mathrm{S} 130$

-E. lata, on grape, cell-wall changes, S129

Evans, M. R., S13

Evans, N., 657

Eversole, K., 524

Everts, K. L., S17, S21, S95

Exserohilum turcicum, on sweet corn, race 1 and Ht1 gene, resistance, S13

Extension, Plant Disease Notebook, customizing a course, $\mathrm{S} 7$

Fabre, F., 1217

Fagaceae, trees in Japan, mortality, S102

Fahmy, Z. M., 853

Faize, M., 1496

Fakhoury, A. M., S24

Falacy, J. S., S24

Falk, B. W., S99, S100

Farman, M. L., 891

Farrall, L., 1452 
Farrar, J. J., S24

Fatmi, M., S25, S76

Fauquet, C. M., 270, 1485, S110

Faure-Rabasse, S. M., S95

Fauteux, F., S133

Favrin, R., S6

Fayad, A. C., S25

Feil, H, 244, 675

Feil, W. S., 244, 675

Feliciano, A. J., S24

Felts, D., S55, S62

Feng, Y., S38

Fenille, R. C., S25

Ferguson, L. M., S25, S49

Fernandes, C. D., 176

Fernandez, G. E., S25, S49, S85

Fernandez, O., S30

Fernández-Acero, F. J., S14

Fernández-Pavía, S. P., S25

Fernando, W. G. D., S72, S94

Ferrandino, F. J., S91

Ferreira, R. B., 1505

Ferris, H., 747

Ferwerda-Licha, M., S25

Fery, R. L., S8, S82

Fessehaie, A. (Canada), 262

Fessehaie, A. F. (Georgia), S88

Festuca arundinacea, leaf spot, biocontrol with

Lysobacter enzymogenes, 1103

Fett, W. F., S26

Fichtner, E. J., S26

Ficke, A., 547, 556

Fieselmann, D. A., S121

Figueira, E. L. Z., 917

Figuli, P. J., S72

Filion, M., 229, S132

Fisher, A. J., S26

Fisher, R. F., S108

Fist, A. J., 752

Fitt, B. D. L., 657, S10, S88

Fitzsimmons, S. P., S120

Flaherty, J. E., S97

Flax, pasmo, fungicides for, $\mathrm{S} 10$

Fleer, J. M., S26

Fletcher, J., 18, 1233, 1240, S64, S89, S94

Flier, W. G., 382

Flowers, J. L., 1471, S26

Floyd, A., S22

Fogg, M. L., S26, S133

Fogle, D., S47

Foissac, X., 644

Fomitopsis pinicola, oxalate partitioning in liquid culture, calcium and magnesium effect, S77

Forbes, G. A., S28, S116

Foreman, G. L., S26

Forest

- ecosystems in world, exotic pathogen protection, S119

- spruce-fir ecosystem, decline in North Carolina, $\mathrm{S} 10$

- wood stake decomposition, in northwestern USA, S74

Förster, H., 923, S21, S127

Forster, R. L., 683, 1430, S81

Foshee, W. G., S76

Foster, K. A., 1165

Fought, L., S128

Fouly, H. M., S27

Fowler, G. A., S56

Fowler, L., S41

Fraedrich, S. W., S18, S27

Fraile, A., 1422

Francis, D. M., S39

Franckowiak, J. D., 604

Francl, L. J., 397

Frank, S., S114
Frankliniella occidentalis, Tomato spotted wilt virus vector on pepper, spread, 1223

Fravel, D. R., S27

Frazer, J. T., S27

Frazier, B. E., 805

Frederick, R., S16, S43, S55, S58, S102, S103

Freeman, S., 219, 579

Fregene, M., S4

Freitas-Astua, J., S5, S54, S82

French, N. M., II, S46

French, R., S27, S38, S78, S99

French-Monar, R. D., S27

Frey, P., 421

Frick, M., S54

Friedland, S. I., S121

Friel, C. J., S128

Friesen, T. L., 397, SS3

Fritz, A. K., 784, S18

Fritze, D., S117

Frost, K. E., S27

Fry, J., S78

Fry, W. E., 382, 738, S7

Fu, Z., S108

Fuentes-Davila, G., S29

Funck Jensen, D., S104

Funderburk, J. E., S115

Fungicides (general) (see also Fungicides, specific)

—adjuvants, efficacy impact, S113

-application, factors, S113

-barley, powdery mildew, population affected by, 305

—demethylation inhibitor, Monilinia fructicola

and hygromycin B resistance, relations, 1354

— discovery targeted, S114

— greenhouse applications, S118

-modes of action, S113

-Phytophthora spp., novel, microbioassay, 46

- powdery mildew on vegetable crops, mixtures, S114

-resistance evolution, S39

-resistance management: FRAC, S114; marketing, science, and politics, S114; scheduling problems, S114; turfgrass pathogens, S114

—resistance risk assessment, S113

— silicon amendments, plant-microbe interactions, $\mathrm{S} 133$

—on tree fruits, resistance problems, S114

- triazole, brown rot control, limitations, S113

Fungicides (specific) (see also Fungicides, general)

- azoxystrobin, synergism with serenade, disease control, S93

-Dazomet, forest nurseries, methyl bromide alternative, S42

- propamocarb and mefenoxam, Pythium on flower crop greenhouses, S135

-strobilurin, Pyricularia grisea resistance, mutations, 891

-trifloxystrobin and tebuconazole, registation update, $\mathrm{S} 128$

Furtado, E. L., S70

Fusarium spp.: on asparagus, $\mathrm{NaCl}$ and rhizobacteria, 186; on corn and pearl millet, fumonisin, in Georgia, S42; on many crops, Bacillus isolate antagontisic to, S15; in soil, wheat cover crop effect, S43; toxigenic, PCR detection, S9; toxins from, $\mathrm{S} 98$

$-F$ circinatum, on conifers, monoterpene in sap resin, $\mathrm{S} 128$

$-F$. graminearium: on maize, phenolics as resistance factors, S97; on maize, resistance factors, ferulic acid and pericarp, 712; on wheat, deoxynivalenol and mapping trait loci, S19; on wheat, head blight epidemic, risk assessment model, 428; on wheat, multien- vironment trial, inoculation comparison for resistance, 1068

-F. oxysporum: on basil, PCR-real time identification, S70; on basil, vegetative compatibility tests, soil isolates, S23; on chickpea, races 0, 1A, 5, and 6, PCR assay, 200; on chickpea, races and fingerprinting with DNA, S41; on cotton, California isolate characterization, S45; genomic sequence in pathogenic and nonpathogenic isolates, S133; on lettuce, gene sequences, PCR detection method, S59; on melon, resistance gene mapping, markers, S42; pathogenic and biocontrol isolates, gene differences, S27; on radish, Pseudomonas putida for control, 626; on spinach, population dynamics, selective media, 1173; on sugar beet and spinach, variability, S33; on tomato, avirulence characteristics, 1360; on tomato, race 3 origin in California, 1014; on tomato, strain interactions, S125; wilt symptoms and ethylene expression, $\mathrm{S} 128$

-F. pseudograminearum, on wheat: genetic tolerance, S79; genotype reaction, S129

-F. solani: on bean, mycorrhizal relation, PCR and direct isolation, 229; on caladium tuber, new clades, S64; gene comparison with yeast, S51; on pea and bean, PR gene activation, transcription, S46; on soybean, gene analysis, during infection, S51; on soybean, image analysis of chromatograms, S83

$-F$. verticillioides: amylase, inhibited by hydrophobic amylase from corn, 917; on corn, detoxification genes, S29; on maize, fumonisin biosynthesis, regulatory genes, S97; on maize, systemic infection and temperature, S64; metabolite for Bacillus mojavensis, S6

Fyffe, A. E., S81

Gabriel, D. W., S15, S59

Gadoury, D. M., 547, 556, S28, S44, S60

Gaeumannomyces graminis

- on bentgrass, pathogenicity determination, S83

- transformation, hygromycin resistance, melanin effect, S27

-on wheat, fluorescent Pseudomonas spp. effect on decline soil, 54

Gafni, Y., S109

Gaitán-Solís, E., 88

Gale, L. R., 610, 1014

Gallaher, R. N., S88

Gallego, G., 88

Galloway, H., S24

Gal-On, A., 1478

Gamble, B., S32

Ganley, R. J., S65

Ganske, D., S58, S78, S90

Gao, B., S21, S23, S28

Gao, H., S52

Gao, X., 1006

Garay-Serrano, E., 382, S25

Garbelotto, M., S28

Garcia, M. E., S8

García-Arenal, F., 941, 1422

Garibaldi, A., S70, S80

Garkovich, L., S119

Garner, J., S11

Garnier, M., 644

Garnsey, S. M., S101

Garrett, K., S18, S28, S53

Garrido, C., S14

Garvin, D. F., S80

Garzon, C. D., S28, S124

Garzón, S., S6

Gaudet, D., S54

Gaugler, R., S103

Gay, P. A., S28 
Geddens, R., S58, S78, S90

Gehmann, K., S113

Geiser, D. M., S28, S42, S50, S64, S124

Geminiviruses, host gene expression, S109

Genomes, NBS-LRR-encoding genes, S110

Genomic analysis, De!CIFR, system, S12

Genomics

- comparative and functional, in fungi, S109

-microbe initiative, plant-associated, letter to editor, 524

Gent, D. H., S29

Geraats, B. P. J., 813

Geranium

-Pythium root rot, fertilizer and biocontrol effect, S135

-Ralstonia wilt, agro-bioterrorism regulation case, S4

Gergerich, R., S40, S85, S95

Gerik, J. S., S29, S77

German, T. L., S101

Gessler, C., 493

Ghabrial, S. A., S94, S95

Ghanmi, D., S133

Ghebreiyessus, Y., S17

Ghimire, S. R., 236

Gianinazzi-Pearson, V., 966

Gibberella zeae

-on corn residue, temperature and moisture effect on perithecia, S133

-spore deposition, night, S77

-on wheat: epidemics in Kansas and North Dakota, 874; rain splash dispersal, in canopy, S23

Gibbons, J., S41, S49

Gibson, D. M., S44

Gibson, R. W., S5

Giesler, L. J., S39, S95

Gijzen, M., 323

Gilbertson, R. L., 478, 596, S109, S111

Gildow, F. E., S100

Gillaspie, A. G., Jr., S29

Gilles, T., 413

Gillian Turgeon, B., S109

Gilligan, C. A., 616

Gimenes-Fernandes, N., 502

Ginseng

-Alternaria blight, necrosis-inducing toxin, spore germination, 323

-Cylindrocarpon destructans, root rot, detection and molecular differentiation, 1533

Girard, M., 1478

Gisi, U., S113

Gitaitis, R. D., 528

Giverns, W. A., S48

Glasheen, B. M., S18, S29

Glauber, J. W., S120

Gleason, K. I., S23

Gleason, M. L., 513, 1285, S7, S22, S23, S35, S46, S86

Glenn, A. E., S6, S29

Glogoza, P., S60

Glomus intraradices, on bean, relation to $\mathrm{Fu}$ sarium solani, PCR, 229

Goates, B., S29

Goddard, A. J., S35

Godoy, C. V., S103

Gold, S. E., S46, 524

Goldbach, R. W., 96, 1223

Goldman, P. H., S29

Gomar-Tinoco, D., 1513

Gomez, L., S30

Gómez-Guillamón, M. L., 844

Gonsalves, D., S78

González, E. (North Carolina), S30

Gonzalez, E. T. (Wisconsin), S30

González, R., 485
Goodwin, S. B., 738, 1158, S2

Gordon, M. P., S108

Gordon, T. R., S128

Gorski, L., S69

Gottwald, T. R., 502, 832, 1031, 1543, S9, S12, S19, S70, S120

Goulds, A., S10, S88

Gourbière, F., 1437

Gourlie, J. A., S79

Gowda, M., S40

Graham, J. H., S17

Grand, L. F., S8

Grape

-Botrytis cinerea, resistance correlations, 1263

- downy mildew, warning system, S44

- epiphytic pathogens, in California, S24

- esca and environmental factors, S24

-Eutypa dieback, detection, S76

-fungal population in vineyards, S14

_-gray rot, defense reaction and latency, 316

- Longidorid nematodes, ribosomal genes and specific primers, 160

-methyl bromide alternative, replant, S77

-ontogenic resistance, flower heterogeneity, S28

- osmotin and thaumatin from, defense mechanism, 1505

-Petri and esca disease, Pennsylvania and New York, 524, S81

- phialophora-like fungi from, molecular systematics, S54

- Phomopsis cane and leaf spot, prediction system, S65

-Pierce's disease: fimbrial genes, 675; inoculation date effect, 244; messenger and particle film, S84

- powdery mildew: humidity effect, 1137; management using aerobiological data, S132; mite suppression, S60; ontogenic resistance, 547, 556

-yellows, insect vectors, Virginia, S7

Gray, F. A., S36, S80, S130

Gray, S. M., 1131, S13, S30

Greene, I. D., S29

Gregoire, T., S60

Gregos, G., S76

Greve, L. C., S74, S129

Grevesse, C., 1145

Grewal, S., S106

Grichar, W. J., S60

Griffin, R. L., S119

Griffin, T. S., S48

Griffith, G. S., 381

Griffiths, B. S., 1111

Grigal, D. F., S47

Groose, R. W., S36

Gross, D. C., S43, S88

Grove, G. G., S24

Groves, R. (North Carolina), S115

Groves, R. L. (California), S30

Growth, hyphomycetes on agar media, cellulose substrate, $\mathrm{S} 72$

Grunden, E., S56

Grünwald, N. J., 382, 738, S25, S30, S86, S107

Grybauskas, A. P., S21

Guaragna, M. A., S30, S57

Gubler, W. D., S24, S113, S129, S130

Gudmestad, N. C., 293, S67

Guerber, J. C., S112

Guérin, G., 219

Guerra-Moreno, A. S., S30, S57

Gugino, B. K., S31

Guhl, K. E., S31

Guilhabert, M. R., S31

Gullino, M. L., S70, S80

Gunasinghe, U. B., S31

Gundersheim, N. A., S34
Guo, B. Z., S31, S52, S55

Guo, L. Y., S31

Guo, M., S108

Guo, Y., S88

Gupta, S. C., S90

Gutierrez, L., S106

Gutiérrez, W. A., S31, S36

Haag, P., S66

Habibi, J., S6

Hadwiger, L. A., S31, S46, S108

Hagan, A. K., S32

Hagiwara, H., 1173

Hakiza, G., S50

Halgren, A., S32, S85

Halik, S., S133, S134, S135

Hall, A., S67

Halley, S., S10

Halterman, D. A., S32

Ham, J. H., S32

Hamamouch, N., S32

Hamblin, A. M., S41

Hameed, K. M., S3

Hamelin, R. C., S8, S41, S98, S132, S134, S136

Hamer, L., S114

Hamm, A., Jr., S80

Hamm, P. B., 805, S113

Hammerschmidt, R., S118, S121

Hammes, G., S20

Hammond, J., S32

Hammond, R. B., S5

Hammond, R. W., S32

Hammond, T. M., S33, S97

Hampton, R. O., S44

Han, S. I., S38

Han, S.-S., 1378

Hancock, J. F., S79

Haney, R. L., S104

Hanley-Bowdoin, L., S109

Hanna, J. W., S33

Hanna, L., S2

Hanna, W. W., S90

Hansen, E. M., 121, 790, S93, S102

Hansen, J. L., S52

Hansen, J. M., S80

Hansen, M. A., S124

Hansen, N. C., S16

Hanson, L. E., S33, 1606

Hao, G., S33

Hao, J. J., 443, S33, S91

Hara, A. H., S4

Harbour, J., S78

Haring, M. A., 1360

Harman, G. E., S104

Harmon, P. F., S33

Harness, A. M., S34

Harnik, T. Y., S28

Harp, T. L., S34

Harrell, M., S39

Harrington, T. C., 901, 1274, S83

Hartman, G. L., S17, S35, S51, S83, S88, S103

Hartman, J. R., 1471, S26

Hartman, R., S10

Hartung, J. S., 953, S51

Hartzog, H., S6

Harveson, R. M., S34

Harvey, J. L., S10, S88

Hasenstein, K. H., S45

Hashim, J. M., S84

Hassan, M. H., S2

Hatcher, W. L., III, S34

Hatfield, J., S40

Haudenshield, J. S., S34, S133

Hausbeck, M. K., S22, S118

Havens, W. M., S95 
Hay, F. S., S34, 752

Hayden, K., S28

Haye, I. I., S75

Haynes, J. G., S31, S34

He, J., S107

He, S. Y., S108

Hebbar, P. K., S20

Hedberg, J., S68

Heidel, G., 720

Heidenreich, M. C., S84

Heiniger, R., S114

Held, L. J., S130

Helicotylenchus dihystera, on sugarcane, conducive and suppressive soils, 1437

Helland, S., S7, S86

Helminthosporium victoriae, mycovirus infection, cellular RNA-binding effect, S95

Henkels, M. D., S11

Henn, A., S68

Henneberger, T., S34

Henning, S., S27

Henriquez, J. L., S35

Heong, K. L., S116

Hepperly, P. R., 1124

Herbicide, glyphosate and atrazine, degradation in soil from mixture, microbial activity, S104

Hermann, D., S113

Herms, D. A., S9, S48

Hernandez, A. G., S51

Hernández, L., S4

Hernandez, S., S35

Herren, H., S116

Herrero, S., S35

Herzog, Z., 356

Hess, D. E., S90

Hess, N. J., S35

Heterodera spp.: on Arabidopsis, ethylene signal transduction, S91; on Arabidopsis thaliana, MCM gene PROLIFERA, 35

-H. glycines: biocontrol with Hirsutella spp., S123; cellulases, characterization, S28; N-Viro soil effect, S93; parasitism proteins, immunodetection, S21; parasitism proteins, plant nuclear import, S23; similarity of genes in nematode and Arabidopsis, S88

- H. latipons, on cereals, root rot comparison, Mediterranean area, S77

-H. schachtii: soil suppression, fungi involved, S67; soil suppressiveness, fungal rDNA, fingerprinting, 1006; on sugar beet, trap crop radish for, S80; on sugar beet, trap crops, S130

Hibiscus, tobamovirus from, diagnostic technique, $\mathrm{S} 42$

Hicks, T. E., S17

Hidaka, S., 1560

Hiebert, E., 774, S89

High plains virus, on corn and wheat, detection in New Zealand, S49

Hildebrand, P. D., S11, S35

Hilf, M., S35

Hill, A. L., S33

Hill, C. B., S35

Hill, H., S41

Hill, J. H., S103

Hillman, B. I., S18, S29, S36

Hinton, D. M., S6

Hirano, S. S., 1082

Hirooka, E. Y., 917

History, plant pathology in North Carolina, S122

Hixson, A. C., S36

Hjeljord, L. G., 1593

Hobbs, H. A., S35

Hodgkiss, I. J., 236

Hoff, T., S89

Höfte, M., 813, S19, S20

Hogenhout, S. A., S84
Hoisington, D., 153

Hoitink, H. A. J., 1292, S37, S118

Hokanson, S. C., S79

Holbrook, C. C., S31, S52, S55

Hollaway, G. J., S36

Hollingsworth, C. R., S36

Hollowell, J. E., S36, S125

Holm, M., S78

Holm, R. E., S11

Holub, E. B., S89

Honda, K., 1560

Hong, C. X., 822, S36, S47, S123, S124, S125

Hong, S. G., S36

Hong, Y. K., S36, S37, S38, S49

Hoogenboom, G., S44

Hopkins, D. L., S37

Hoplolaimus galeatus, on creeping bentgrass, population dynamics in Kansas, S78

Hopp, H. E., 136

Hops

- powdery mildew, temperature effect on infection, 1587

—viruses, spread in Australia, S71

Horn, B. W., S59

Hornsby, S., S10

Horrell, J., S15

Horst, L. E., S37

Hosta spp., Sclerotinia rolfsii petiole rot, oxalic acid and resistance, S46

Host-pathogen interactions, dominance effect, coevolution in pathosystems, 633

Hotchkiss, M. W., S73

Houfek, T. D., S21

House, B. L., S77, S108

Howard, E. F., S5

Howard, R. J., S22

Howd, D., S30, S63

Howell, C. R., S21, S37, 1606

Hsu, M. P., S15

Hsu, S. T., S52, S53

$\mathrm{Hu}, \mathrm{S}$., S94, 1115

Huang, G., S37

Huang, H. C., S52, S53

Huang, J.-S., S91

Huang, X., 35

Hubble, H., S37

Hüberli, D., S28

Hudelson, B. D., S4, S26

Hudler, G. W., S82

Huerta-Espino, J., 153, 881, S112

Hughes, L., S93

Hulbert, S., S54, S94

Hull, R., S111

Humbert, C., S125

Hunt, B., S113

Hunt, T. E., S95

Hurtado, P. X., S4

Hurtt, S. S., S51

Hussey, R. S., S21, S23, S28, S37, S88

Husson, C., 421

Hutchens, A., S38

Hutchinson, J. L., S38

Hwang, B. K., S38

Hwang, J. (North Carolina), S38, S118

Hwang, J. B. (Korea), S37

Hyde, K. D., 236

Hypovirulence, Sclerotinia homoeocarpa and Ophiostoma novo-ulmi mitovirus, 1407

Hyun, J. N., S36, S37, S38, S49

Idris, A. M., 774, S38

Ignatov, A. N., S9, S38

Impatiens balsamina, Rhizoctonia solani, composted potting mix effect, 1115

Inderbitzin, P., S98

Ingle, C. A., S64
Integrated pest management, Alternaria leaf blight on carrot, case study, 1320

IR-4

-biopesticide program, grants and regulatory assistance, $\mathrm{S} 11$

-project: fungicide registation update, S83; registration, crop grouping, efficacy data, S16 Iriarte, F. B., S39

Iriki, N., S65

Iris yellow spot virus, $\mathrm{N}$ gene, diversity in USA, S1

Irrigation

—disinfestion, ultraviolet irradiation, S123

-Phytophthora nicotianae, detection with PCR, 822

- pythiaceous species in water, PCR template preparations, $\mathrm{S} 124$

Isakeit, T., S39

Ishida, M. L., S50

Ishiguro, K., 1560

Ishimaru, C. A., S29, S39

Islam, S. Z., S39

Ismael, A.-S. M., 853

Isshiki, A., 768

Ito, S., S102

Ittu, M., 1068

Ives, A. R., S91

Ivors, K., S28

Jabaji-Hare, S., 229, S136

Jackson, T., S6

Jacobi, W. R., 1037, S47

Jacobsen, B. J., S7, S117

Jaffee, B. A., 1599

Jahn, R., S39

Jaime, M. D. L. A., S39

Jaime-Garcia, R., 1190, S39

James, R., S39

Jamir, Y., S108

Janes, M. D., S108

Janisiewicz, W. J., S40, S50

Jansky, S. H., S27

Jantasuriyarat, C., S40, S41

Jara, C., 88

Jarret, R., S16

Jeffers, S. N., 46, 822, S23, S63

Jellison, J., S77

Jenkyn, J., S10, S88

Jensen, B., S104

Jensen, P. J., S40

Jensen-Tracy, S. L., S82

Jeong, J. S., S40

Jermini, M., 493

Ji, J., S40

Jia, L., S40

Jia, Y., 1452, S40, S41

Jiang, H., S109

Jijakli, M. H., 1145

Jiménez-Díaz, R. M., 200, 1513, S41

Jiménez-Gasco, M. M., 200, S41

Jin, Y., 604, S93

Jo, Y., S41

Jobin, T., S41

Jochum, C. C., S93

Johnson, A. M., S41

Johnson, C. S., S41

Johnson, D. A., 805, S42, S43, S66

Johnson, E., S71

Johnson, H. A., Jr., 380

Johnson, K. B., S82

Johnson, V., S41

Johnston, D., 712

Johnston, S. A., S26, S133

Joly, D. L., S41, S134

Jomantiene, R., S124

Jones, A. L., 1393 
Jones, A. T., 71

Jones, D., 720

Jones, J. B., 535, 1415, S21, S27, S62, S66, S74

Jones, J. D., S41

Jones, J. P., S74

Jones, S. S., S50

Joobeur, T., S42

Joosten, N. N., 96, 1223

Joppa, L. R., S80

Jordan, D., S70, S78

Jordan, K. S., S62

Jordan, R. L., S30, S57

Joshi, M., S13

Joshi, R., S106

Julotok, M., S13

Jung, G., S15, S72, S73, S76

Jung, H. J., S42

Jurgenson, J. E., S19

Jurjevic, Z., S42

Juzwik, J., S42, S101

Kabir, Z., S131

Kadir, J., S75

Kaeppler, H. F., 860

Kahn, M. L., S77, S81, S108

Kaiser, R., S114

Kakar, R. S., S17

Kalat, S., S21

Kalloo, G., 1485

Kaloshian, I., 35

Kamenova, I., S42

Kanaan-Atallah, Z., S42, S43

Kaneko, A., S69

Kanematsu, S., 1560

Kaneshiro, W. S., S43

Kang, H. (Texas), S43

Kang, H. W. (Korea), S36

Kang, M. H., S43, S66

Kang, S., 1378, S43, S45

Kangatharalingam, N., 1204

Kannenberg, E., S34

Karakashian, A., S2

Katan, J., 1247

Kataoka, T., 42

Kavanagh, K., S131

Kayim, M., S20

Kazmierczak, P., S85

Kean, D., S44

Keen, N. T., 18

Keinath, A. P., S43

Keith, L. M., S43

Keizer, L. C. P., 666

Kelemu, S., 176, S43

Keller, B., 493

Keller, K. E., S44, S58, S85

Keller, M., 316

Keller, N. P., S33, S97

Kellerhals, M., 493

Kelley, A. T., S48, S49

Kelly, J. D., S70

Kemerait, R. C., Jr., S11, S44, S123

Kemmitt, G. M., S67

Kenerley, C., S21, S60

Kennedy, G., S1, S79, S115

Kennedy, R., 413

Kennelly, M. M., S28, S44

Kenney, D. S., S117

Keremane, M., S71

Kers, J. A., S13, S44

Keurentjes, J. J. B., 626

Kexian, Y., 176

Khalid, S., 1422

Khan, J., S44

Khan, M. F. R., S44

Khan, N. I., S44

Khan, V. A., S81
Khang, C. H., S45

Khangura, R. K., 1073

Kharbanda, P. D., S45

Khosla, S., S118

Khush, G. S., 147

Kianian, S., 397

Kiewnick, S., S45

Kilaru, A., S45

Kilic-Ekici, O., 1103

Kim, D. H., S42, S45, S69

Kim, E. S., S69

Kim, H. J., S45

Kim, H. T., S38

Kim, J. H., S45

Kim, K. W., S89

Kim, M. J., S45, S69

Kim, M. S. (Hawaii), 1124

Kim, M.-S. (Idaho), S33, S74

Kim, S. (Suwon, Korea), 82

Kim, S. C. (Milyang, Korea), S36, S37, S38, S49

Kim, S. K. (Chonju, Korea), S42

Kim, Y. (California), S45

Kim, Y. H. (Korea), S45

Kim, Y.-S. (Кy.), 891

Kindt, F., 626

King, J. J., S42

Kinkel, L. L., S106

Kinloch, B. B., Jr., 691, 1044

Kirk, W. W., 1400

Kirkpatrick, B., S31, S74

Kirkpatrick, T. L., S46, S104

Kishi, L., S82

Kistler, H. C., 1014

Kitajima, E. W., S4, S54

Kleinschmidt, C. E., S46

Klessig, D. F., S15, S47

Klietman, F., 931

Kloepper, J. W., 1301, S117

Klopfenstein, N. B., S33, S73, S74

Klosterman, S. J. (Georgia), S46

Klostermann, S. J. (Washington), S46, S108

Knodel, J., S10, S60

Knoedler, J., S125, S135

Knudsen, I. M. B., S104

Knudson, D. L., S39

Kobaisy, M., S68

Kobayashi, D., S51, S73, S108

Kobori, T., 1445

Koch, C. A., S86

Koch, D. W., S80, S130

Koehler, K. A., S46

Koehn, A. C., S81

Koeller, W., S113

Koerbler, M., S5

Koh, J. M., S38

Kohls, C., S120

Kohn, L. M., S39, S98

Koike, S. T., S28, S29, S47, S127

Kolmer, J. A., S67

Konczal, K. M., S89

Kondo, H., S36

Kong, P., 822, S36, S47, S124

Kopp, H. T., S78

Korndörfer, G. H., 256

Koski, R. D., S47

Kosman, E., 1464

Kotcon, J. B., S47

Kraft, J. M., S30

Kral, C., S78

Krall, J. M., S130

Kramer-Haimovich, H., S105

Krasnoff, S. B., S44

Krattiger, A. F., S111

Krause, C. R., S37, S118

Krause, M. S., 1292, S52

Krauss, U., 1274
Kreitman, M., S83

Kremer, R. J., S104

Kristjansson, G., S8

Kritzman, G., 356, 931

Kromroy, K. W., S47

Kroon, L. P. N. M., 382

Krutz, L. J., S104

Kucharek, T. A., S89

Kuck, K.-H., S114

Kudrna, D., S40

Kuhajek, J. M., 46

Kuldau, G. (Georgia), S6

Kuldau, G. A. (Pennsylvania), S97, S98

Kulemeka, B. P., S34

Kulkarni, R. D., S47

Kumar, D., S47

Kumar, K. A., S90

Kumar, P. L., 71

Kumar Choppakatla, V., S48

Kuniyasu, K., 1173

Kuniyuki, H., S111

Kunkel, D. L., S11

Kuramae, E. E., S25

Kurle, J. E., S16

Kushalappa, A. C., S55, S72

Kuti, J. O., S48

Kwak, D. Y., S49

Kwon, B. R., S42

Kyde, K. L., S84

Kyo, M., 768

Labavitch, J., S74, S129

Labbé, C., S74

Labonne, G., 1543, S19

Lacava, P. M., 953

Lacy, G. H., S76, S125

Laflamme, G., S135

Laforest, J. H., S48

Lagoke, S. T., S3

Lalancette, N., 1165

Lamari, L., 391

Lambert, K. N., S39

Lamondia, J. A., S48

Lamour, K. H., S118

Lan, Z., 1581

Landa, B. B., 982, S20

Landschoot, P. J., S112

Lang, D. L., S31

Langston, D. B., Jr., S77, S82, S113

Lanier, J., S78

Lapaire, C. L., 193

Larkin, R. P., S11, S48

Laroche, A., S54

Larrue, J., 1308

Larsen, R. C., S48

Latham, S. R., S24

Latin, R., S33

Laux, P., S2

Laverdiere, L., S34

Lawrence, C. B., 813, S18, S62

Lawrence, G. W., S38, S48, S49

Lazarowitz, S. G., S110

Leach, J. E., 524, S53, S57, S94

Leandro, L. F. S., 513, 1285, S49

Lecoq, H., 1478

Lee, B. C., S36, S37, S38, S49

Lee, D. C., S37, S49

Lee, D. K., S43, S66

Lee, E., S57

Lee, F. N., S40, S49, S79

Lee, H. K., S48, S49

Lee, I.-M., 1368, S2, S49

Lee, K. S., 147

Lee, K. W., S38

Lee, R. F., S8, S30, S49, S57, S71, S86

Lee, S. C., S38 
Lee, Y.-H., 82, 1378

Lee, Y. S., S50

Legac, J., S106

Legard, D. E., S61

Lei, C., S57

Leite, B., S4, S50

Lemanceau, P., 966

Lennon, K. A., S59

Leonard, K. J., 860, S71

Lepo, J. E., S71

Lepoivre, P., 1145

Leptosphaeria maculans, on canola:

-biocontrol antifungal compounds, S72

—model for predicting ascospore showers, 1073

Lerner, J. M., S134

Lertsuchatavanich, U., S50

Leslie, J. F., 853, 874, S19, S93

Lesourd, M., 1023

Leterrier, J. L., 1217

Letousey, P., 451

Letter to the editor

-microbe genome initiative, plant-associated, 524

-multilocus correlation, parameter for plant pathogen population study, 1464

Lettuce

-bacterial leaf spot: etiology and epidemiology, S74 genetic diversity of pathogen, 596; pathogenic variation, 64

-drop, Sclerotinia spp., sclerotia and soil moisture and temperature, 443

-drop, temporal and spatial dynamics, Sclerotinia minor sclerotia, irrigation and tillage effect, 1572

-leaf spot, bacterial population effect, S29

- Phoma basal rot, in California, S47

- powdery mildew, chemical management, evaluation, S58

-tombusvirus, soil environment effect, S101

Leung, H., S57, S113

Leveau, J. H. J., S106

Leverentz, B., S50

Lévesque, C. A., 262, S6, S8, S52, S66, S132

Levin, J. S., S23

Levy, C., S103

Levy, L., S59, S121

Lewellen, R. T., S54

Lewers, K. S., S79

Lewis, W. J., S42

Lewis Ivey, M. L., 64, S50

Lherminier, J., 1308

Li, F., S107

Li, H. J., S50

Li, H. W., S107

Li, R., 1301, S51

Li, S., S51, S83

Li, T., S79

Li, W.(Nebraska), S105

Li, W.-B. (Maryland), 953, S51

Li, W. X. (California), S107

Li, X., S51

Li, Y. H., S52

Li, Z., S52

Liang, H., S52

Liang, X. Q., S52

Liao, C.-H., S52

Lieghard, R., 493

Lievens, B., S52

Liew, E. C. Y., 236

Lim, T. H., S128

Lin, H. X., S100

Lin, X., 1258, S94

Lin, Y. C., S52, S53

Lin, Y. H., S52, S53

Linde, C. C., S53

Lindow, S. E., 675, 727, 1209, S106, S120
Linholm, K. M., S53

Lipps, P. E., 428, S17, S20, S23, S53, S133

Listeria monocytogenes, on cabbage, transcription, S69

Liu, B., S53

Liu, H.-Y., S54

Liu, J. Q., 959

Liu, L., S51

Liu, Q., S95

Lizarraga, C., S116

Llano, G. A., S4

Locali, E. C., S54

Logrieco, A., S98

Lohar, D. H., S108

Loke, J. B., S4

Long, L. A., S54, S81

Long, S. R., S108

Longidorus sp.

-on loblolly pine, bare fallow effect, S18

-in pine seedlings, chemical treatments, S27

Loper, J. E., S11, S72, S82, S108

Lopes, J. R. S., S4

López, C. E., 88

López, M. M., 286, 485

López, R., 1553

López-Gerena, J., S54

López- López, M. J., 485

Loppnau, P., S134

Lorbeer, J. W., S34, S133

Loria, R., S13, S44, S121

Louws, F. J., S22, S25, S49

Lowe, R., S113

Lozoya-Saldaña, H., 382

Lu, G., S40

Lu, R., S107

Lu, S.-E., S88

Lu, Y. J., S54

Lu, Z.-X., S54

Lübeck, M., S104

Lucas, W. J., S109

Lucca, F., 136

Luce Carlson, K. M., S54

Lugo, Y., S74

Lui, L. H., S55

Lukach, J., S10

Luke, E., S121

Lundeen, P., S66

Luo, D., S128

Luo, M., S55

Luo, Y., 102, S55, S56, S128

Luster, D., S43, S55

Lutton, E., S106

Luvisi, D., S84

Lyerly, J. H., S55

Lynch, J. P., S45

Lynch, R. E., S31, S52

Lyngkjaer, M. F., S112

Lysobacter enzymogenes

- antifungal antibody from, S51

-biocontrol agent: secretory pathway, S73; for turfgrass and bean, root growth inhibitor, S51

— biocontrol of leaf spot in tall fescue, 1103

Ma, R., S55

Ma, Z., S55, S56, S128

Maas, J. L., S79

Macdonald, W. L., 1039

Machado, C., S97

Machado, M. A., 28, S5, S54, S82

MacHardy, W. E., S133

MacKasmiel, L. A., S56

Mackey, B. E., 1263

Mackey, I. C., S85

Macroptilium lathyroides, on bean, new begomoviruses, 774

Madariaga, R. B., S56
Madden, L. V., 428, 458, 995, 1292, S20, S23, S28, S37, S53, S65, S92, S133

Magarey, P. A., S44

Magarey, R. D., S56

Magnaporthe spp.

-M. grisea: cDNA library, SMART and recombinational cloning, S40; on foxtail millet, host specificity, wheat and foxtail millet crosses, 42; pathotypes and fingerprint haplotypes, in Korea, 1378; on rice, BAC shotgun libraries, sequencing, S82; on rice, chromosome 7 analysis, S83; on rice, gene screening, $\mathrm{S} 22$; on rice, mesophyll cell, cover photo, May; on rice, $\mathrm{Pi}$-ta resistance locus, variation, 1452; on rice, protein interaction with adenylate cyclase and kinase, S47; on rice, silicon effect, ultrastructure and cytochemistry, 535; on rice and turfgrass, rice defense genes, $\mathrm{S} 41$

- M. oryzae, on ryegrass, detection method, S33

Mahaffee, W. F., 1587, S105

Mahovic, M. J., S56

Mahrer, Y., 1247

Maier, T., S37, S59, S88, S91

Maize (see also Corn)

-aflatoxin resistance in lines, protein association, $\mathrm{S} 12$

-Fusarium graminearum, resistance factors, ferulic acid, 712

- gray leaf spot, environmental effect, S70

- late blight, diversity and amplified fragment length polymorphism, Egypt, 853

- northern leaf blight, resistance, S112

-trichome, microcycle conidiation of Cercospora zeae-maydis, cover photo, February

Maize fine streak virus, host range and genome sequence, S84

Majerczak, D. R., S61

Makalowska, I., S43

Malnoy, M., 1496

Maloney, P. E., S28

Maloney, S. C., S77, S108

Malouin, C., 712

Malvick, D. K., S56

Manio, P. D., 1052

Manjuanth, K. L., S8, S30, S57, S86

Manosalva, P., S57

Mansour, M., 1263, S69

Manter, D. K., 121

Manulis, S., 356, 931

Manuscript preparation, author's guide, 7

Maragos, C. M., S46

Marais, L. J., S8

Marco, C. F., 844

Marco, M. L., S106

Marcus, R., 931

Margosan, D. A., S57

Maris, P. C., 96, 1223

Mark, G. L., S34

Marois, J. J., S115

Maroon-Lango, C., S32, S57

Marot-Leblond, A., 1023

Marquardt, S., S57

Marques, L. L. R., S57

Marsella, M., S49

Marshall, L., S113

Martin, F. N., S10, S57, S58

Martin, G. B., S110

Martin, K. J., S71

Martin, M., S58, S78, S90

Martin, R. M., S128

Martin, R. R., S32, S44, S58, S85

Martin, T. J., S78

Martinez, C., S132

Martínez, E., S71

Martínez, M. C., 136 
Martínez del Pozo, Á., 1344

Martinez-Espinoza, A. D., S46

Martinez-Ochoa, N., S19, S58

Martini, M., 1368

Marucci, R. C., S4

Marvel, J., S58, S124

Materne, M. D., S74

Matheron, M. E., S58, S114

Matheson, F., 167

Mathews, H., S58

Mathre, D. E., 751, 959

Mathur, S., S130

Matveeva, E. V., S9, S38, S58, S65

Maurhofer, M., S3

Maust, B. E., 976

Mavrodi, D. M., 982, S20, S58, S108

Mavrodi, O. V., S58

Mavrodieva, V., S59

Maxson-Stein, K., 1393

Maxwell, D. P., S75

May, K. J., S59

Mayama, S., 42

Mayberry, K. S., S85

Mayfield, J. D., S69

Maymon, M., 219, 579

Maynard, C. A., S52

Mazarei, M., S59

Mazumdar-Leighton, S., S78

Mbofung, G. M., S59

McAlpin, C. E., S59

McBeath, J. H., S28

McBride, P. O., S31

McClean, P. E., 1430

McCormick, W. A., S15

McDaniel, P. A., S74

McDonald, B. A., 941, S53

McDonald, G. I., S33

McDonald, J., S8

McDonald, V. T., S129

McDowell, J. M., S89

McEvoy, J. L., S69, S105

McFadden, A. G., S67

McGee, D., S64

McGhee, G. C., 1393

McGovern, R. J., S64, S74

McGrath, M. J., S60

McGrath, M. T., S59, S134

McK Bird, D., S76

McKee, K. A., S74

McKinley, N., S78

McLaughlin, S. T., S12

McLaughlin, W. M., S75

McLean, K. S., S38, S48, S69

McMahon, M. B., S55

McManus, P. S., S87

McMullen, C. R., 1533

McMullen, M., S10, S60

McNally, D. J., S74

McNellis, T. W., S40

McRae, K. B., S35

McSorley, R., S88

McSpadden Gardener, B. B., S100, S106, S117

Meacham, T. E., S78

Medeiros, F. H. V., S60

Mei, C., S60

Mejía, J. F., S4

Melampsora spp.

-M. larici-populina, on poplar, resistance, leaf disk bioassay, 421

-M. medusae, on poplar, control in stool beds, S128

Melcher, U., 1233. 1240, S64, S94

Melidossian, H. S., S60

Mellado, M. Z., S56

Mellon, J. E., S60

Meloidogyne spp.: on Arabidopsis thaliana,
MCM gene PROLIFERA, 35; host responses, $\mathrm{S} 76$; plant cell surface changes from infection, $\mathrm{S} 31$

-M. arenaria, infection with species of Moniliales, S61

-M. artiellia: on chickpea, interaction with Fusarium oxysporum, race 5, 1513; on chickpea roots, cover photo, December

-M. baetica, on olive, in Spain, 1093

-M. incognita: on corn, root border cell presence, 1111; on maize root, cloud of detached cells, cover photo, September; parasitism genes, subtractive strategy, S37; on tomato, biocontrol with Paecilomyces lilacinus, S45; on tomato, biocontrol strategy, S73

-M. javanica, isothiocyanate sensitivity, laboratory assay, 747

-M. partityla, on pecan, resistant rootstocks, S66

Melouk, H. A., S16, S60, S76

Melton, T. A., S31

Melzer, M. S., S14

Mendelssohn, I. A., S74

Méndez-Lozano, J., 270

Mendiola-Olaya, E., 917

Mendoza-Herrera, A., S60

Menelas, B., S61

Menge, J. A., S129

Mengistu, A., S61

Menkir, A., S12

Menzies, J. G., 167, 402, S74, S133

Mercier, J., S61

Mergoum, M., S3

Merighi, M., S61

Mertely, J. C., S61

Meruliporia incrassata, oxalate partitioning, calcium and magnesium effect in culture, S77

Mervosh, T. L., S48

Meyer, M. C., S25

Meyer, S. L. F., S2, S61

Meyers, B. C., S110

Miao, H., S61

Michailides, T. J., 102, S55, S56, S62, S128

Michel, F. C., Jr., 1292

Michelmore, R., S110

Michelutti, R., S62

Michoski, C. E., S72

Microbial ecology, genotypic diversity data, analysis, 738

Microclimate, greenhouse, factors and manipulations, S118

Microdochium nivale

—on bentgrass, resistance assay, S15

-on turfgrass, variation in Wisconsin, S73

Microorganism populations, geneotypic diversity data, analysis, 738

Miedaner, T., 1068, S19

Mikkelsen, L., S104

Miklas, P. N., 683, S48, S81

Mikota Gabler, M., 1263

Mila, A. L., 758, S62

Milat, M,-L., 1308

Miles, M. R., S103

Milgroom, M. G., 738, 1378, S41

Miller, D. R., S16

Miller, G., S82

Miller, J. D., S80

Miller, S. A., 64, S50

Miller, T. A., S8

Miller, T. C., S113

Milligan, B. G., S132

Mills, D., S53

Milus, G., S3

Milyutina, I. A., S9

Ming, R., 1124

Minsavage, G. V., 1415, S62, S66
Minz, D., 219, 579

Mirza, M., S45

Mitchell, D. J., S81

Mitchell, F. L., 1233, 1240, S94

Mitchell, T., S18, S22, S59, S62, S82, S83

Mitkowski, N. A., S62

Mitter, V., S3

Miyao, E. M., 1014

Mmbaga, M. T., S5, S62, S63, S66

Mo, A. Y., S42

Model

-blackleg sporacle, ascospore shower in canola, 1073

-durable resistance, measures, 616

- gene-for-gene, wheat tan spot, 391

- gray leaf spot of ryegrass, temperature and leaf wetness duration, 336

- linear approach, disease in spatial hierarchy, 458

-Phomopsis amygdali on peach, temperature and moisture effect on sporulation, 1165

-risk assessment, wheat Fusarium head blight, epidemics, 428

-ryegrass stem rust, degree-hour wetness duration and predictions, 467

-soilborne pathogens, survival under solarization, 1247

- Swiss needle cast on Douglas-fir plantations, Oregon, 790

-weather-based forecasting, foliar fungal plant pathogens, S56

Modeling, NAPPFAST, weather-based mapping of plant pathogens, S56

Moënne-Loccoz, Y., 1437

Moffett, K., S63

Mohan, K., S115

Mohan, S. K., S1

Moldenhauer, K., S41

Moldovan, M., 1068

Molecular markers, phenotypic analyses and epidemiology, S107

Molinéro, V., 1023

Momol, M. T., S66, S115

Mondal, S. N., 1031, S63

Monier, J-M., 1209

Monilinia spp.

-M. fructicola: on canned peaches, cover photo, November; hygromycin B resistance, fungicide susceptibility and sporulation effect, 1354, on plum, latent infection, S55; on prune, latent infection and threshold conditions, 102; on stone fruit, benzimidazole resistance, in California, S56

-M. vaccinii-corymbosi, on blueberry, pollen mimicry by conidia, S65

Monosporascus cannonballus, pentaketide and hexaketide metabolites, analysis, S90

Monteiro, S., 1505

Montón, C., 485

Moore, G., S71

Moore, J. A., S33, S74

Moore, M. (Texas), S17

Moore, M. K. (Washington), S16

Moore, P. H., 1124

Moore, P. P., S127

Moorman, G., S28, S45, S124, S135

Morales-Payan, J. P., S63

Morandi, E. N., 136

Moreno, A. B., 1344

Moreno, I. M., 1422

Morgan, D. P., S55, S62, S128

Morgan-Jones, G., S69

Mori, M., 1173

Morin, C., S134

Morrell, J. J., S119

Mortimer, M. M., S77, S108 
Morton, A., 364

Moyer, J. W., S1, S55, S79, S84, S99, S115

Muangsan, N., S109

Muehlbauer, F., S16

Mueller, D. S., S63

Mueller, J. D., S82

Muller, G. W., S82

Mundt, C. C., S28, S100, S107

Mungbean, bruchid resistance, defensin, S15

Munkvold, G. P., S64, S70

Murakami, J., 42

Murata, M., S102

Murillo, J., 1553

Murillo-Williams, A., S64

Murphy, J. F., 1301, S34, S64, S117

Murray, T. D., 650, S50, S65, S87

Murray, W. K., S47

Muscodor albus, biofumigant, green mold and sour rot of lemon and gray mold rot of grape, S61

Mushroom, shiitake, leachate for bacterial wilt control, S68

Muskmelon, vine decline, cultivar susceptibility, S85

Mutaqin, K. H., S64

Mycorrhizae, arbuscular, symbiosis-related genes, cloning, S134

Mycosphaerella spp.

$-M$. citri: ascospores, release and dispersal factors, 1031; on citrus, mating behavior and pseudothecial ontogeny, S63; on grapefruit, epidemiology and control, S63

- M. graminicola: host resistance response, S22; on wheat, resistance gene, molecular mapping, 1158

Mycotoxin

- aflatoxin, cottonseed contamination, in Texas, 1190

- food contamination, Africa, factors, S116

-ochratoxin: in grape and wine, S99; in small grains, S99

-RNAi and model system, Aspergillus, S97

Myers, J. R., 683, 1430, S44, S81

Myxobacteria, plant pathogens lysed by, S12

Na, S. Y., S43, S66

Nagy, M. A., S97, S98

Naidu, R. A., S64

Nakamura, Y., 1228

Nakayashiki, H., 42

Nalim, F. A., S64

Nameth, S. G. P., S91

Nascimento, L. C., S64

Nash, M., S17

Nault, B. A., S78

Navas-Cortés, J. A., 1513

Navi, S. S., S65, S92

Nawar, H. F., S48

Nazaret, S., 1437

Ndum, O., S30

Negatu, A., S17

Nelson, B. D., S65

Nelson, D., S130

Nelson, G., S114

Nelson, R. J., S28

Nematicides, preplant organic acid, for nematodes on tomato and strawberry, S62

Nematodes

—entomopathogenic, transgenic, risk, S103

- population dynamics, winter cover crops in Florida, S88

-root-knot, egg recovery from roots, methods, S129

- soil fumigation and oxamyl drip, in vegetable plasticulture, insects, S20

Nematode-trapping fungi, activity and most prob- able number correlation, 1599

Neotyphodium sp., in forage grasses, anti-mammalian toxin genes, S97

Nerad, T., S13

Nester, E. W., S108

Nester, S. E., S10

Neumann, P., S41

Nevins, D. J., S128

New Pest Advisory Group, potential within USA, S41

New, S., S1, S55

Newcombe, G., S65, S129, S131

Newman, M. L., S29

Ngugi, H. K., S65

Nguyen, K.-P., S82

Niblett, C., S57, S71

Nicole, M., 1308

Nikolaeva, E. V., S58, S65

Nischwitz, C., S65, S129

Nishio, Z., 1228, S65

Nita, M., 995, S65

Nitric acid synthase, pathogen-inducible, on Arabidopsis and tobacco, S15

Nitric oxide, synthase in higher plants, gene cloning attempt, $\mathrm{S} 91$

Nitrogen, stable isotope ratios, hosts and parasites, S129

Nitzan, N., S66

Niu, X. F., S66

Nnodu, E., S63, S66

Noh, T. H., S43, S66

Nolasco, G., 278

Nolin, S., S22, S42

Nordheim, E. V., S91

Norelli, J. L., S66

Norman, D. J., S21

Norton, G., S116

Nourrisseau, J.-G., 644

Nunes, J., Jr., S103

Nutter, F. W., Jr., 210, 513, 1285, S24, S61, S103

Nyczepir, A. P., S66

Oak (see also Quercus spp.)

-decline, in Europe; in eastern USA, S102

- ecosystem dominated by, in world, S102

-Phytophthora diseases, S102

- sudden oak death, chemical treatment strategy, S28

—wilt, epidemic in USA, S102

—worldwide disease threat, S101

Oak, S. W., S102

Oat, crown rust, seedling resistance, 860

Oberle, C. S., S90

Obermeier, C., S101

Obituaries

-Charles Lee Campbell, 381

—Robert Harry Stover, 916

—Stephen Wilhelm, 380

Obradovic, A., S66

O'Brien, P. A., 695

Ocamb, C. M., 1587

Ochiai, N., S67

Ochoa-Corona, F. M., S49, S67

Odvody, G., S39

Oelke, L. M., S67

Oemichen, B., S67

O'Gorman, D., S66

Ohki, S. T., 1445

Ohtani, K., 768

Okoli, C. A. N., 364

Olano, C. T., S71

Olatinwo, R. O., S67

Olaya, G., S1, S67

Old, K., 1524

Olivain, C., S125

Olive
- Pseudomonas savastanoi, RNA viruses, reverse transcription-PCR, 286

-root-knot nematode, new species in Spain, 1093

Oliveira, M. M., 278

Olivier, C., S67

Olmos, A., 286

Olsen, M. W., S10

Olson, B. D., S67

Olson, M. E., S57

Olson, M. V., S108

Olson, S. M., S115

Omarov, R., S68, S95

O'Neill, T., S47

Onion

-Botrytis blight, airborne conidia, S14

-Ditylenchus dipsaci, root exudates and chemo attractant, 127

_pink root, cultivar susceptibility, S77

Opgenorth, D., S76

Ophiosphaerella herpotricha, bacterial-mediated transformation, S62

Ophiostoma spp., REMI transformation, S135

-O. novo-ulmi, mitovirus, conspecific with Sclerotinia homoeocarpa, hypovirulence, 1407 Oppenheim, D., 356, 931

Orabi, J., 391

Orange, Xylella fastidiosa, on fruits and seeds, seedling transmission, 953

Orchid, pathogenic bacteria, characterization, S43

Orobanche spp.

-O a agytiaca, host resistance enhance by sarcotoxin IA, S32

-O. cernua, on tomato, salinity effect on germination, S3

-O. ramosa, on Arabidopsis thaliana, defense gene expression analysis, 451

Oropeza, C., 976

Ortiz Islas, S., 153

Osaki, T., 1445

Osborne, L. E., S93

Osterbauer, N. K., S68

Oszako, T., S102

Otaye, D. O., S68

Otrosina, W. J., S68

Oudemans, P. V., S20

Ouellet, T., S97

Overton, B. E., S54, S81

Ownley, B. H., S11

Ozakman, M., S68

Özdemir, Z., S134

Pacumbaba, R. O., Jr., S68

Pacumbaba, R. P., S68

Pagani, M. C., S68

Page, K., S68

Page-Dumroese, D. S., S74

Paguio, O. R., S64

Pair, S. D., 1233, 1240, S94

Paiva, W. M., S103

Palermo, S., S89

Palmateer, A. J., S69

Palmquist, D. E., S86

Palou, L., S69

Palumbo, J. D., S69

Pan, H., S83, S114

Panaccione, D. G., S97

Pandey, P. K., 1485

Panella, L., S33

Pannu, S. S., S72

Panter, S., S105

Pantoea stewartii

-alternative host survey, in Iowa, S24

-on corn: flea beetle populations, infestation, 210; lon protease as regulator of protein secretion system, S32 
—hrp response regular, S61

Papalas, J., S82

Papaver somniferum, downy mildew, epidemic analysis, symposium, 752

Papaya ringspot virus

-geographic strains: resistance, cover photo, January; resistance in coat protein, 112

-on weeds, in Puerto Rico, S25

Pappu, H. R., S69

Paradornuwat, A., S50

Paris, R. L., S61

Parisi, L., 1496

Park, E., S69, S105

Park, J., S27

Park, S. M., S45, S69

Park, S.-Y., 1378

Park, Y., S69, S105

Parke, J. L., S93

Parker, K. C., S8

Parker, P. E., S9, S70

Parker, S. R., 1329

Parkhill, J., S39

Parry, D., 364

Partridge, D. E., S70

Partridge, J. E., S26

Pascholati, S. F., S4

Paspulum, nematodes, susceptibility, S36

Pasquali, M., S70

Pasteuria penetrans, nematode relations, on golf greens, S135

Pastor-Corrales, M. A., S70

Pataky, J. K., S13, S46, S112

Pathogens, population study, parameter measure with multilocus correlation, letter to editor, 1464

Patocchi, A., 493

Paul, P. A., S70

Paulitz, T. C., 867, S77

Pauls, K. P., 712

Pauls, K. P., S97

Paulsen, I., S107, S108

Payne, G. A., S24

Payton, M., S76

Pea

-Aphanomyces root rot, PCR assay, S86

—calico, vector transmission, S44

-Fusarium root rot, resistance sources, S30

-nonhost resistance response, comparison in animal cells, $\mathrm{S} 108$

-root rot, biocontrol with Clonostachys rosea, 329

-virus resistance in transgenic plants, S24

Pea enation mosaic virus, on transgenic pea, S24

Peach

— canker, sporulation, temperature and moisture effects, 1165

- chitinase, glucanase, and lyase induced in, by UV treatment, 349

-Ilarviruses, horizontal spread in orchards, S130

—rust: fungicides and management, S130

- scab, conidial dissemination and infection, 1581

- Sharka disease, spatial pattern analysis in France, 1543

Peanut

-aflatoxin contamination: field factors, S10; phytoalexins and resistance, $\mathrm{S} 31$

-calcium nutrition effect on disease, S76

- Cylindrocladium black rot, metam sodium and axoxystrobin applications, in Georgia, S123

—disease management, AU-input advisory, S44

—early leaf spot, maize intercrop effect, S10

-irrigation, disease management, S78

-leaf spot and southern stem rot, cropping frequency and severity, S32

-Pythium pod rot, irrigation effect, S48
—Sclerotinia blight, epidemiology factors, S80

- Sclerotinia minor: detached part susceptibility, S80; genoype, tissue, and isolate effects, S125; resistance, transgenic plants, $\mathrm{S} 16$

— southern blight, field resistance, S60

— southern stem rot, spray advisories, S125

—-spotted wilt, vulnerability, S115

-tebuconazole application, air and ground sprays, S11

-Tomato spotted wilt virus on, resistance evaluation, S64

Pear

—blight, genetic analysis in Japan, 1393

-bull's eye rot, etiology and epidemiology, S35

-fire blight: biocontrol, temporal dynamics, 727; diagnostic medium and sampling procedure in orchards, 931; warning system in Israel, 356

- postharvest fruit rot, Washington, S92

Pecan, bark canker, unknown etiology, S73

Peck, A. R., S124

Pedraza, F., 88

Peever, T., S16, S107

Peltamigratus christiei, on turfgrass, other nematode comparison, S19

Peng, Y.-L., S70

Penicillium spp.

- on stored orange fruit, ozone for control, S69

Penman, L. N., S70

Pennisetum glaucum, on striga, resistance, S90

Pensuk, V., S64

Peoples, K., S114

Pepino mosaic virus, detection and characterization, S57

Pepper, anthracnose:

- fungicides, S124

-isolate characterization in Virginia, S58

Pepper golden mosaic virus, isolate variation, begomovirus complex, S38

Pepper huasteco virus, Pepper golden mosaic virus interaction, 270

Pepper mottle virus, systemic infection, resistance nature, S34

Peres, N. A. R., S70

Perez, B. A., S71

Pérez-Laorga, E., 485

Perkins, J. M., S112

Pernezny, K., S74

Peronosclerospora sorghi, on sorghum, metalaxyl treatment, Texas, S39

Peronospora arborescens, on oilseed poppy, in Australia, epidemic, symposium, 752

Pesic, Z., S85

Pest management

-insect, communication, S116

-vectors, international development issues, S116

Pesticides, residue, reduction in export crops, S116

Peters, D., 96, 1223

Petersen, Y., S71

Peterson, C. J., S129

Peterson, D. L., S40

Peterson, G. L., S10

Peterson, P. D., 381, S71

Pethybridge, S. J., S71

Petnicki-Ocwieja, T., S108

Petrillo, M. D., S76

Pfammatter, W., 493

Pfender, W. F., 467

Pfister, S. E., S134

Phaeoacremonium spp., on grape, teleomorph report, S129

Phaeocryptopus gaeumannii, on Douglas-fir:

-distribution in Idaho, S131

—quantification methods, 121 —severity prediction in Oregon, 790

Phaeosphaeria nodorum, on wheat, triticale, and rye, pathogenesis, $\mathrm{S} 90$

Phakospora pachyrhizi, on soybean, world production and year-round establishment, S71

Phaseolus spp. (see also Bean): Pseudomonas syringae in phyllosphere, factors, 1082

$-P$. vulgaris: angular leaf spot, integrated management strategy, in Canada, S14; disease resistance, gene analogs, 88; halo blight, nontoxigenic strains, Spain, 1553; two new begomoviruses, 774

Pheasant, J., S121

Phialophora gregata, on soybean, two races, characterization in north-central USA, 901

Phillips, L. L., S71

Phillips, P. A., S19

Philogène, B. J. R., 712, S97

Phlox, potexvirus on, characterization, S32

Phoma sclerotioides, on alfalfa, disease reaction, S36

Phomopsis spp., on cotton, species comparison on soybean, S69

- P. amygdali, on peach, sporulation, temperature and moisture effects, models, 1165

- P. obscurans, on strawberry, visual estimation reliability, 995

-P. vaccinii, on cranberry, upright dieback, S14

$-P$. viticola, conidial release, pattern in New York, S82

Phylloplane, microbial population dynamics, leaf as determinant, S91

Phyllosphere

-bacteria: expression technology, S106; gene expression, S106

-flow cytometric application, S106

-laboratory model, effectiveness, S106

-microbial diversity, challenges, S106

-microbial interaction, microscopy, S105

-microbial populations on plant surfaces, S105

-Pseudomonas syringae, bean, factors, 1082

- space and time translation, S106

-spatial distribution, S106

Phytophthora spp.: on citrus, PR-4 protein, S17; on floriculture crops, etiology, S118; on floriculture crops, in North Carolina, S38; on fruit and nut crops, genetic diversity, S8; fungicides, novel, microbioassay, 46; morphological and molecular characterization, integration, S1; on oak, molecular marker systems, S58; on ornamental plants, species characterization, S23; population decline from retention pond, S36; species origin, hybridization role, S98; waterborne, temperature effect on cyst germination, S68

-P. capsici: on chile, soil salinity effect, S75; genetic diversity of isolates, $\mathrm{S} 10$; genetic variation in Illinois, S84; host range in Illinois, S83; mefenoxam sensitivity, in New Jersey, $\mathrm{S} 26$; on pepper, management, S22; on pepper, mefenoxam sensitivity, S133; on pumpkin, genetic diversity and variation, S39; soil dispersal, agroecosystems, S53; in vegetable farms, weed association, S27

-P. cinnamomi: on avocado, suppression in soil, S129; on woody plants, clonal lineages in Australia, 695

-P. cryptogea, on witloof chicory, biosurfactants, S19

-P. infestans: A1 mating type loci, DNA marker, S50; freezing tolerance, genotypes, 1400; molecular evolution, S30; on petunia, factors, $\mathrm{S7}$; on potato, irrigation, aerial photography for spatial pattern analysis, 805; on potato, metalaxyl, China, S31; on potato, population variation, Nepal, 236; on potato, resistance 
factors, 666; soilborne vs. aerial populations, in central Mexico, S25; on Solanum spp., in Mexico, 382; spore showers in highland tropics, S28; virulence variation, asexual progenies, 293

$-P$. inflata, host range, $\mathrm{S} 82$

$-P$. nicotianae: in irrigation water, detection with PCR, 822; on weeds, in nurseries, S125

$-P$. parasitica: in composted swine waste, suppression, S26; on tobacco, elicitin-induced protection, cytology, 1308

$-P$. ramorum: conflicts with researcher and the public, S121; on oak, associated vegetation in Oregon, S93; on oak, detection method in plant tissue, ribosomal DNA, S47; on oak, detection using PCR, S8; on oak, factors, S12; on oak, resistance, S84; sudden oak death cause, host range, S28; survey in Oregon, S68

$-P$. sojae: on soybean, characterization using PCR, S54; on soybean, defense-related genes, S87; on soybean, major soybean Rps genes, Illinois, S56; on soybean, race changes in Iowa, S66

-P. tritici-repentis, race 8, in North America, S4

Phytoplasma

- ash yellows, aggressiveness in North Dakota, S88

- aster yellows epidemic, molecular analysis, Texas crops, 1368

- aster yellows group, insertion sequence, S49

- Candidatus Phlomobacter fragariae, on strawberry, in French fields, 644

—coconut, lethal yellowing, carbohydrate metabolism, 976

- on oak, campion, thistle, and dandelion, RNA interoperon sequence heterogeneity, S124

-on tobacco, elicitin-induced protection, cytology, 1308

Phytosanitary Alert System, North American Plant Protection Organization, function, S6

Piçarra-Pereira, M. A., 1505

Pichia anomala, on apple, biocontrol role, exoglucanase-encoding gene, 1145

Pierce, M. L., 1204, S7

Pierson, E., S108

Pierson, L. S., III, S108

Pietravalle, S., 1329

Pigeonpea sterility mosaic vector, mite transmission, divided RNA genome, 71

Pilcher, C. D., S46

Pine

-loblolly: decline in Alabama, soil factors, S35; fungal elicitors, S44; fusiform rust, growth effect, $\mathbf{S} 88$

-longleaf, prescribed burning effects, S68

- stem rust, Cytochrome P-450 genes, molecular analysis, S41

Pingel, R. L., S25

Pinon, J., 421

Pinus spp., Scleroderris canker, phenols, pectin, and callose involvement, S135

$-P$. banksiana, rust and mycoparasite, $\mathrm{S} 136$

$-P$. monticola, blister rust, resistance gene $\mathrm{Cr} 2$, origin, 691

$-P$. nigra, Sphaeropsis tip blight, detection with PCR, 1471

$-P$. radiata, Dothistroma needle blight, hyperspectral imagery for assessment, 1524

Pioli, R. N., 136

Pistachio, panicle and shoot blight, risk assessment in California, S62

Pitluck, H. M., S121

Pittman, R. N., S60

Pivonia, S., S71, S103

Plant doctor

—diagnosis, control, S122 -what is it? S122

Plantegenest, M., 1217

Plasmopara halstedii, on sunflower, structural and immunochemical changes, 1023

Platt, H. D., S116

Plaza, P., S69

Pleosporaceae, mating type genes and breeding system, S98

Ploetz, R. C., 916, S71

Plourde, K., S135

Plum, brown rot, IPM system, S128

Plum pox virus

-host adaptation and memory, S100

-on peach, spatial pattern analysis, 1543, S19

Pocasangre, L., S96

Podosphaera spp.

-P. macularis, on hops, temperature and infection severity, 1587

-P. xanthii, on cucurbit, strobilurin fungicides, resistance, $\mathrm{S} 59$

Poe, S., S121

Poinsettia, Pythium root rot, biocontrol, S8

Pokorny, J., S42

Polashock, J. J., S72

Poling, E. B., S25

Polityko, V., S9, S38

Polymorphism, analysis, pathogen identification, S124

Polymyxa graminis, soilborne virus vector, 1131

Pomella, A. W., S20

Ponciano, G., S53

Pond, E., S129

Pons-Kühnemann, J., 305

Poplar

- abscisic acid, water stress and compartmentalization, S135

- hybrid, leaf rust, leaf disk bioassay, 421

-leaf rust, molecular epidemiology, S132

Populus spp., canker disease epidemic, in Wisconsin, S89

Porchas, M., S58

Porter, D., S48

Porter, J. K., S6

Postharvest disease, key to identification, onion metabolites, S72

Postharvest pathology

-apple diseases, biocontrol with yeasts, oxidative stress, 564

-apple fruit decay, control with Candida saitoana, 344

-Candida sake for apple fruit disease, 436

- peach UV-C treatment, chitinase, glucanase, and lyase induced by, 349

Postnikova, E. N., S2, S76

Potato (see also Solanum spp.)

-bacteria, differentiation of, oligonucleotide array, 262

- common scab, streptomycete variation, S89

- disease diagnostics, Brazil, S111

- dry and soft rot of tuber, specific metabolites, S55

- early dying, soil factors, multiple linear regression to model, S67

-famoxadone and cymoxanil for control, S78

-late blight: alleles and epidemic relation, S107; chitosan/copper applications, S31; Global Initiative, S116; irrigation, spatial pattern analysis, aerial photography, 805; population variation, Nepal, DNA polymorphisms, 236; resistance factors, 666; tuber rot, foliar fungicides, S67; virulence variability, 293

—pink-eye, S67

- Rhizoctonia disease, biocontrol and ryegrass rotation, $\mathrm{S} 11$

-Rhizoctonia solani, anastomosis group 3, North Carolina, 610 —scab, phytotoxin, bacterial nitric oxide synthase, S44

- Sclerotinia stem rot, Washington, S43

- silver scurf, chlorine for control, S85

- soilborne diseases, biological products and green sprouting, $\mathrm{S} 48$

- soilborne pathogens, Brassica crop rotation, S48

-Streptomyces turgidiscabies, mobile pathogenicity island, S13

-viruses: detection by RT-PCR, S2; emerging and re-emerging, $\mathrm{S} 101$

Potato mop-top virus, detection in seed potato, RT-PCR, S92

Potato spindle tuber viroid, on tomato, host components, S32

Potato virus $Y$

—on potato, molecular characterization, S78

- virus movement in tubers, patterns and timing, S30

Potebniamyces pyri, on pear, distribution in Pacific Northwest, S92

Potting media, biocontrol agent substrate, S118

Powell, W. A., S52

Powelson, M., S67

Prabhu, A. S., 256

Pratt, R. G., 1565, S72

Pratylenchus spp.: on field crops in Australia, S36; on field crops, Pacific Northwest, S125; on wheat, genetic tolerance, S79

-P. penetrans: on alfalfa, resistance affected by oryzacystat I and II, 799; on pyrethrum, in Australia, S34

Press, C., S72, S108

Pria, W. D., Jr., 953

Primula, commercial hybrid, Botrytis cinerea seed infection, latent disease spread, 573

Prithiviraj, B., S55, S72

Pritts, M. P., S84

Private practitioners

- getting started, S120

-insurance, disease losses, S120

-nonscientific issues, S120

- science and consulting, people problems, S120

-university and regulatory agency, interfacing, S120

Procunier, J. D., 167

Prune dwarf virus, in almond, reverse transcription-PCR, 278

Prunus spp., brown rot, latent infection and threshold conditions, 102

Prusky, D., S105

Pruvost, O., 832

Pryor, B. M., S36, S59, S72, S99, S128

Pseudomonas spp.: on conifers, antibiotics produced in rhizosphere, PCR-based detection, S132; take-all decline soils, antibiotic production, 54

-P. aeroginosa: host range in plants and animals, mechanisms, S107; on lettuce, seed germination and seedling growth, S52; on tomato, Ralstonia solanacearum relation, S53

-P. cichorii, on coffee, distribution in Puerto Rico, S75

-P. corrugata, nonpathogenic mutants, biocontrol agents, S73

-P. fluorescens: biocontrol agent, gene expression profile, S72; biocontrol agent for pear, temporal dynamics, 727; genomics and biological control, S108; PCR detection of phenotypes, S20; on pear and apple, iron bioavailability, S82; pyoluteorin from, biocontrol agent, $\mathrm{S} 11$; root colonization, genes, $\mathrm{S} 58$; in wheat rhizosphere, 2,4-diacetylphloroglucinol-producing strains, interactions, 982

$-P$. huttiensis, on tomato, new in greenhouse, S66 
-P. putida, Fusarium wilt of radish controlled by, 626

-P. savastanoi, on olive, RNA viruses, detection, reverse transcription-PCR, 286

$-P$. syringae: on bean, nontoxigenic strains, Spain, 1553; on cereals, glume rot in Russia, S9; leaf environment response, cell size reduction, 1209; pathogenicity and genomics, S108; on Phaseolus vulgaris, spread in phyllosphere, factors, 1082; recombinant mutants, legel impediments, S120; RND transporter, characterization, S43; syringopeptin produced by, factors, S88; on tomato, genomics, sequences, $\mathrm{S} 110$

Pseudoperonospora humuli, outbreaks in crops in Argentina, S71

Puccinia spp., rusts on daylily and geranium, fungicide effect, $\mathrm{S} 63$

$-P$. allii, on leek, inoculum density and temperature effect, germination, 413

$-P$. coronata, on oat, seedling resistance, quantitative trait loci, 860

- $P$. graminis: population changes in Minnesota, $\mathrm{S} 71$; on ryegrass, infection prediction, degreehour wetness duration, 467

$-P$. hordei, on barley, molecular mapping of resistance gene, 604

$-P$. lagenophorae, on groundsel, biocontrol concerns, $\mathrm{S} 123$

-P. striiformis, on wheat: gene markers, 881; resistance and molecular markers, 153

-P. triticina: on wheat, gene markers, 881 ; on wheat, molecular markers, 153

Puchalski, B., S54

Puckhaber, L. S., S37, S90, 1606

Pumpkin

-Fusarium fruit rot, cover crop mulches, S91

- spray programs and cover crop effect, S17

Punja, Z. K., S69

Purcell, A. H., 244, 675

Purteka, G., S84

Purugganan, M., S84

Puthoff, D. P., S59

Putter, T., S49

Pyrenopeziza brassicae, on oilseed rape, epidemic development in United Kingdom, 657

Pyrenophora tritici-repentis, on wheat:

-novel isolates, S3

-Ptr ToxA sensitivity, 397

-two races and one-to-one relation, 391

Pyricularia grisea

-on Lolium perenne, temperature and leaf wetness duration, model, 336

-on ryegrass: USA and Japan comparison, S86; vegetative compatibility assay, USA and Japan comparison, $\mathrm{S} 87$

-strobilurin resistance, gene mutation, 891

Pythium spp.: on bermudagrass roots, stems, and leaves, in Florida, S81; on carrot, molecular characterization in California, S24; 2,4-diacetylphloroglucinol effect, sensitivity variation, 966; in greenhouse, diversity and pathogenicity, S125; identification using AFLP, S124; population genetic studies, AFLP markers, S28; in wheat fields, communities, Washington, 867

$-P$. aphanidermatum, on turf, fungicide resistance mechanism, target site, S67

-P. festivum, on corn, morphological and molecular characterization, $\mathrm{S} 1$

$-P$. oligandrum, on sugar beet and wheat, defense reactions, cell wall protein fractions, 1228

Qin, Q. M., S70

Qin, X., 953

Qiu, W., S68
Qualle, S., S10

Quayyum, H. A., 323

Quercus spp. (see also Oak)

-bark canker and drippy nut, characterization in Spain, 485

Quiot, J. B., 1543, S19

Raaijmakers, J. M., 54, 966

Radewald, K. C., S129

Radish

-bacterial leaf spot, compost rhizobacteria, severity suppression, 1292

-Fusarium wilt, biocontrol with Pseudomonas putida, 626

Radopholus similis, thermotolerance induced, absence, S4

Ragatz, R., S72

Rahme, L. G., S107

Rains, G. C., S42

Rajagopalan, R., S22

Ralstonia solanacearum

-on geranium, race 3 , biovar 2, S65

-on ginger, molecular diversity in Hawaii, 1124

-on potato: detection of race 3 in tuber, S68; virulence and diversity in Russia, S58

- secretome role in pathogenesis, S30

- on tomato, chemotactics and virulence, S93

Ramarathnam, R., S72

Ramesh, C. R., 176

Ramirez, H., S90

Ramming, D. W., 1263

Ramon, M. P., S135

Rampersad, S. N., 1153

Randal Schadel, K., S62

Randhawa, N. K., S72

Randhawa, P. S., S72

Rangel, Y., S73

Rasabandith, S., 147

Rascon, J., S37

Rasmussen, J. B., 397, S3

Raspberry, decline, aphid-transmitted virus, S32

Raspberry bushy dwarf virus, resistance, S58

Rathayibacter toxicus, on annual ryegrass, toxicity and strains, S2

Rayside, P. A., S81

Rebordinos, L., S14

Reddy, D. V. R., 71

Reddy, J. D., S73

Reddy, M. S., 1301, S117

Reddy, R. (New Jersey), S108

Reddy, R. K. (India), S65

Redinbaugh, M. G., S73, S84, S87

Reedy, R. M., S73

Reeleder, R. D., 1533

Regnault-Roger, C., 712, S97

Regulatory programs, legal problems, S121

Rehms, L., S68

Rehner, S. A., S61

Reid, L. M., 712, S97

Reilly, C. C., S66, S73

Reimann, S., S73

Reinsel, M. D., S32

Remick, A., S107

Renderos, W. E., S35

Resistance

-alfalfa to root-lesion nematode, oryzacystat I and II effect, 799

-apple to scab: field resistance, mapping, 493; Trichoderma chitinase effect, 1496

- barley to leaf rust, molecular mapping of gene, 604

- bean to Bean common mosaic necrosis virus, NL-3 K strain, 683

- bermudagrass to dematiaceous hyphomycetes,

leaf inoculation technique, 1565

-durability, measures of, 616 -grape to: Botrytis cinerea, resistance correlations, 1263; powdery mildew, ontogenic, 547, 556

- melon to Curcurbit yellow stunting disorder virus, reduced virus accumulation, 844

-oat to crown rust, seedlings, quantitative trait loci, 860

- papaya to Papaya ringspot virus, coat protein gene, 112

- pathogens to bean, resistance gene analogs, 88

- pepper to thrips, Tomato spotted wilt virus, 96

- plant virus durability, analysis, 941

- poplar to leaf rust, bioassay, 421

- potato to late blight, resistance factors, 666

-rice to: bacterial blight, gene mapping, 1258; bacterial blight, inheritance in 21 cultivars, 147; blast, $P$ i-ta locus, 1452

-wheat to: Fusarium head blight, multienvironment trial, 1068; leaf rust, 784; leaf and stripe rust, durable, 153; powdery mildew, silicon role, 402; Septoria tritici leaf blotch, 1158

-white pine to blister rust, gene $\mathrm{Cr} 2,691$

Reviewers, acknowledgment of, 4

Reyna, N. S., S73

Rhizobacteria

- asparagus, Fusarium crown and root rot effect, $\mathrm{NaCl}, 186$

-radish bacterial leaf spot suppressed by, in compost, 1292

Rhizobium leguminosarum, on pea, mutant effect on nodule development, S34

Rhizoctonia spp.: in soil, wheat cover crop effect, $\mathrm{S} 43$

-R. solani: on bean, mycorrhizal biocontrol agent, glucanase, S136; on cowpea, resistance evaluation, S8; on creeping bentgrass, new subgroup in North Carolina, S1; in impatiens, composted potting mix effect, 1115; on potato, anastomosis group 3, population migrants, 610; on rice, blight lesions, cover photo, March; on rice, growth stage and silicon effect, 256; on soybean, ribosomal DNA polymorphism, S25; on tobacco, resistance screening, S23

Rhodes, L. H., S5, S83, S91

Rhopalosiphum padi, Barley yellow dwarf virus vector, yield loss prediction from, 1217

Rhynchosporium secalis

-on barley and rye, speciation, S53

- sexual reproduction, evidence, S53

Rice

- bacteria to elicit resistance, hypersensitivity, S94

-bacterial blight: resistance and gene mapping, 1258; resistance inheritance in 21 cultivars, 147; strain interactions, antagonistic, 705

-blast: defense response genes $\mathrm{S} 40$; durable resistance, S113; durable resistance, QTL characterization, S54; ethylene role in resistance, S79; hypoxia root zone, field resistance, S49; Pi-ta locus, variation, 1452; resistance and marker assisted selection, $\mathrm{S} 41$; resistance genes in Colombia, S18; silicon effect, ultrastructure and cytochemistry, 535

- defense response genes, PCR-based screening strategy, S57

-false smut, management in Nigeria, S3

-MAP kinase, molecular characterization, S73

—phytoalexins, diterpenoid accumulation, S74

- Rhizoctonia solani, isolate diversity, S40

- sheath blight, growth stage and silicon effect, 256

-transgenic: ethylene insensitivity, suppression by EIN-2 ortholog, S95; jasmonate insensitive, generation, S60 
Rice dwarf virus, Korean isolate, RNA analysis and sequence, $\mathrm{S} 49$

Rich, J. R., S46

Richard, J. L., S99

Richardson, B. A., S73

Richardson, P. A., 822, S36, S47, S125

Richins, R., S84

Rick, S., S58, S78

Rico, A., 1553

Rideout, S. L., S123, S125

Riedel, R. M., S91

Riegel, D. G., S90, S91

Riley, M. B., S18

Riley, T., S12, S59

Rimé, D., 1437

Rimelspach, J. W., S83

Rimmer, S. R., 959

Rioux, D., S135

Rioux, S., S6

Rippy, R. C., S74

Ristaino, J. B., S30, S53

Ritchie, D. F., S68

Rivas-Davila, M. E., S32

Rivera, L., S74

Rivera-Bustamante, R. F., 270, S109

Rizzo, D. M., S28

RNA silencing, antiviral defense in plants and animals, S107

Robarge, W. P., S10

Robert, R., 1023

Roberts, D. P., S125

Roberts, P. D., S27

Robertson, C. L., S74

Robertson, D., S109

Robinson, C., S48

Robinson, P. E., S74

Robison, D. M., 1165

Rodermel, S. R., S59, S91

Rodger, S., 1111

Rodrigues, F. Á., 256, 535, S74

Rodriguez, R., S75

Rodríguez-Alvarado, G., S25

Rodriguez-Kabana, R., S81

Roelfs, A. P., S71

Rogers, J. D., S92

Rogers, P. M., S74

Rogers, R., S102

Rojas, M. R., S109, S111

Rolland, D., S14

Rollins, J., S38, S105

Rolshausen, P. E., S129, S130

Ronald, P., 705

Rooney, S. N., S129

Roper, M. C., S74

Rosales, M. I., S86

Roscoe, J., 1233

Rose, rosette disease, spread in southeastern USA, S124

Rosenzweig, N., S75

Rosskopf, E., S75, S92

Rosso, P. H., 790

Rothrock, C. S., S40

Rotylenchulus reniformis

-on cotton, seasonal variation in Mississippi, S49

-tillage and crop sequence effect, depth distribution, 1182

Roumbos, C., S45

Rouse, D. I., S26, S27

Rowden, J., S10

Roy, A., S19, S57, S75

Roye, M. E., S75

Ruegg, D., S3

Ruhl, G., S122

Ruhnke, P., S67

Rungrassamee, W., S135
Rupe, J. C., S125

Rush, C. M., 720, S81

Rutger, J. N., S40

Ryba-White, M., S57

Ryder, E., S29

Ryegrass

- gray leaf spot, field resistance to strobilurin fungicides, 891

- stem rust, degree-hour wetness duration, infection prediction, 467

Rytter, J., S40

Ryu, C.-M., 1301, S117

Saad, A. T., S2

SADIE, disease epidemics, spatial dynamics, statistics study, S92

Saftner, R. A., S50

Saguy, I. S., 1247

Sahin, F., 64

Sakadzic, S., S130

Salam, M. U., 1073

Salar, P., 644

Salas, B., S75

Salazar, L. F., S101

Saleh, A. A., 853

Salicylic acid, binding protein and disease resistance, $\mathrm{S} 47$

Salih, S. S., S51

Sallam, M. A., S2

Samac, D. A., 799

Sams, C. E., S11

Samuels, G. J., S20

Sances, F., S120

Sanchez, L., S75

Sanogo, S., S14, S75, S104

San Segundo, B., 1344

Santamaría, J. M., 976

Santos, F. A., S82

Santoso, A., S75

Sarrocco, S., S104

Satellite panicum mosaic virus, in millet, hostspecific movement, S68

Saucier, M., S107

Saude, C., S76

Savelle, A. T., S76

Schaad, N. W., S2, S9, S25, S38, S50, S58, S65, S68, S72, S76

Schaff, J. E., S76, S108

Schardl, C. L., S97, S98

Scheef, E. A., S72, S76

Scherm, H., S18, S65, S76, 1581

Schiff, N. M., S90

Schilder, A. M. C., S76, S90

Schilling, J. S., S77

Schindelbeck, R. R., 1131

Schisler, D. A., S17, S79, S86, S94, S117

Schmale, D. G., III, S77

Schmidt, D. J., S28

Schmidt, R. A., 1037, 1048

Schnabel, G., 1354, S12, S23, S113

Schneider, D. J., S108

Schneider, J. K., S82

Schneider, R. W., 1014, S13, S74

Schneider, S. M., S77

Schneider, W. L., S100

Schnell, R. J., S71

Scholl, E. H., S76, S108

Scholthof, H. B., S95

Scholthof, K.-B. G., S68

Scholz, U. M., S77

Schrader, K. K., S68

Schroeder, B. K., S77, S108

Schroeder, K. L., S77

Schumann, G. L., S132

Schuster, G., S48

Schwartz, H. F., S29
Schweitzer, P. A., S51

Science and law, expert witness, S121

Sclerotinia spp.: biocontrol agents against, Arizona, S72; sclerotia, germination, soil moisture and temperature, 443

-S. homoeocarpa: on Agrostis sp., biocontrol, $\mathrm{S} 89$; on bentgrass, isolates, S41; genetic diversity, turfgrass species and location, S39; Ophiostoma novo-ulmi virus, specificity, hypovirulence, 1407

-S. minor: on winter wheat, mycelial interaction, S36; on temporal and spatial dynamics, irrigation and tillage effects, 1572

-S. sclerotiorum: apothecia, Salinas Valley, California, S131; ascus maturation, incubation, S70; on canola, biocontrol with Bacillus, S94; cell wall degrading enzymes, repression and regulation, S38; genetic variability and outcrossing, Washington, $\mathrm{S} 42$; on soybean, in north central USA, Bayesian logistic regression, symposium, 758

Sclerotium rolfsii

-on Pulmonaria and Astilbe spp., new hosts, $\mathrm{S} 23$

- survival overwinter, in Iowa, S22

Scoggan, A., S128

Scott, D., S128

Scott, J. B., 752

Scott, S., S41

Scuimbato, G., S68

Sears, J. L., S54

Secor, G. A., 293, S67

Seebold, K. W., Jr., S20, S77

Seem, R. C., 547, 556, S28, S44, S60

Seifers, D. L., S78

Seifert, K. A., 1533, S6, S15

Seijo, T. E., S61, S74

Senesac, A., S123

Senseman, S. A., S104

Septoria tritici, on winter wheat, epidemics, weather models, 1329

Serce, S., S79

Serlemitsos, K., 336

Serratia marcescens, on cucurbit:

— genomic comparison, S94

- genotyping, techniques, 1240

-yellow vine disease, phylogeny, 1233

Setaria italica, crosses with wheat, Magnaporthe grisea, host specificity, 42

Seth, D., S78

Settlage, S. B., S109

Settle, D., S78

Setubal, J., S108

Sewake, K. T., S43

Seyran, M., S61

Shah, D. A., S78

Shamoun, S. F., S104

Shank, K., S100

Shaw, D. S., 236

Shaw, J. N., S10

Shaw, M. (New Mexico), S84

Shaw, M. W. (U.K.), 573, 1329

Shearer, B. L., 695

Shen, Y., 705

Shepherd, C., S58, S78, S90

Sherman, D. J., S100

Sherrier, D. J., S31, S34

Sherwood, J. E., S7

Sherwood, J. L., S5, S64

Shew, B. B., S10, S36, S54, S80, S125

Shew, H. D., 610, S23, S26, S94

Shibli, R., S3

Shiel, P. J., S2, S78

Shields, E. J., S77

Shilts, T., S17

Shim, H. K., S43, S66 
Shim, W. B., S78

Shimerling, O., S81

Shin, M. S., S66

Shishkoff, N., S59, S125, S135

Shlevin, E., 1247, 1320

Sholberg, P. L., S66, S79

Shollenberger, L. M., S52

Shoseyov, O., S81

Sh. Pekhtereva, E., S58

Shtienberg, D., 356, 931, 1320

Shuster, J. R., S114

Shwartz, H., 356, 931

Sica, C. J., S135

Sierotzki, H., S113

Sievert, J. R., S57

Sikora, L. J., S14

Sikora, R. A., S45, S73, S77, S96

Silva, C., 278

Sim, T., IV, S10

Simard, M., S135

Simón, B., 1422

Simpfendorfer, S., S3

Simpson, C. R., S12

Sims, J., S77

Sin, S. H., S79, S99

Singh, M. P., S49, S79

Singh, P., S40

Singh, R. P., 153, 881, S112

Singh, S. (Kansas), 784

Singh, S. P. (Idaho), 683, S81

Sinorhizobium meliloti

- genetic manipulation, S77

-Rhizobium comparison, symbiosis, S108

Sipes, B. S., S4

Sirococcus conigenus

-on conifers, morphology, S12

-host-related groups, molecular markers, S80

Skalchunes, A., S114

Skantar, A. M., S2

Skaria, M., S61

Slattery, M., 46

Slininger, P. J., S79, S86

Smart, J. R., 1182

Smigocki, A. C., 799

Smilanick, J. L., 1263, S57, S61, S69, S105

Smiley, R. W., S79, S125, S129

Smith, A. M., S28

Smith, B. J., 219, S79

Smith, D. L., S80, S125

Smith, D. R., S80

Smith, H. J., S80, S130

Smith, J. J., 1393

Smith, J. P., S43

Smith, K. N., S75

Smith, R. B., 391

Smith-Becker, J., S128

Sniezko, R. A., 691

Snover, K. L., S121

Sobolev, V., S31

Soderlund, C., S40

Sohi, H. S., S72

Soika, M. D., S86

Soil fumigation, methyl bromide, vine, tree, and berry field nurseries, S77

Soil solarization: snapbean damping-off, furfural or urea amendment, S81; soilborne pathogens, survival modeling, 1247

Soil suppression, Heterodera schachtii, oligonucleotide fingerprinting, 1006

Solanum spp. (see also Potato), cultivated and wild, Phytophthora infestans population structure, in Mexico, 382

$-S$. tuberosum, osmotin genes, sequence analysis, $\mathrm{S} 28$

Song, S. B., S36, S37

Sorghum -anthracnose, pathosystem, S111

- grain mold, dew and incubation temperature, S65

Soria, S., 485

Sorrells, M. E., S13

Soto, M. J., 478

Soto-Estrada, A., S130

Souza, A. A., S82

Souza, N. L., S25, S70

Souza-Dias, J. A. C., S111

Soybean

-Bean pod mottle virus on, resistance, S95

- brown stem rot, race distribution in north-

central USA, 901

-Cercospora leaf blight, resistant cultivars, S13

- charcoal rot, disease assessment, S61

- cyst nematode, Geldanamycin effect on, S2

-defense-related genes, Arabidopsis comparison, S59

- green stem incidence, variability in cultivars, S35

-iron-deficiency chlorosis, soil factors in Minnesota, S16

- northern stem canker, field trials in South

Dakota, S15

-Phytophthora sojae, inoculation technique, S65

- pod and stem blight, variability in Argentina, characterization, 136

-root diseases, glyphosate effect, S104

-root rot pathogens, molecular detection, S6

-Roundup Ready, soil effect, S104

-rust: biology and history, S102; breeding programs, history, S103; control in South Africa, S103; defense-related genes, S16; epidemic in Brazil and Paraguay, S103; molecular detection, S102; protein profiles, S55; risk in USA, S103; strategy to minimize establishment, S103

- Sclerotinia stem rot: genetics and QTL identification of resistance, $\mathrm{S} 88$; in north central USA, Bayesian logistic regression, symposium, 758

— stem canker, epidemic in South Dakota, S94

- sudden death syndrome: fungi and tissue of taproots, S92; inoculation technique, S65; molecular basis, $\mathrm{S} 40$

- viruses, distribution in Ontario, S62

-white mold, genomic analysis of resistance, S17

Soybean dwarf virus, aphid vector specificity, readthrough domain relation, 1560

Soybean mosaic virus

-biological diversity of isolates, S25

- evolutionary analysis from clones, S78

-resistance genes, virus tracking movement, S25

- transgenic resistance, models, S103

Spadaro, D., S80

Spaide, R. G., S103

Spartina alterniflora, role in coastal Louisiana, S74

Spatial pattern, analysis, new method, S91

Spear, R. N., S60, S91, S106

Special session presentations, S97

Species concepts, collision, S93

Speck, J., S1

Sphaerellopsis filum, species complex, S65

Sphaeropsis sapinea

-in Austrian pine: defense responses, systemic, S55; detection with PCR, 1471

-on pine, Agrobacterium-mediated transformation, S26

-on red pine, resistance in fertilization, $\mathrm{S} 9$

Spiegel, Y., 127

Spinach

-Stemphylium botryosum and Cladosporium variabile, inoculum source, $\mathrm{S} 22$

-Verticillium wilt, in Washington, S22

-white rust, management and aphid relations, S21

—wilt, selective media, 1173

Spiranthes cernua, potyviruses on, detection, S30

Spiroplasma spp., leafhopper vectors, lectin binding to salivary glands, S89

$-S$. citri, mutants and variants, S64

-S. kunkelii, ATP-binding cassette protein, S95

Spotts, R. A., S35

Springer, P. S., 35

Spurr, H. W., Jr., S80

Stack, R. W., S80

Stagonospora sp., bindweed control by, S3

$-S$. nodorum, on wheat, partial resistance mapping, S124

Stall, R. E., 1415, S62

Stall, W. M., S63

Stanford, M., 1524

Stanger, C., S67

Stanghellini, M. E., S129

Staniulis, J., S124

Stanley, L., S24

Stanley, M., S121

Stanosz, G. R., S12, S80, S89

St-Arnaud, M., 229, S132, S136

Starner, V. R., S83

Steadman, J. R., S70

Steddom, K., 720, S81

Steele, W., S90

Steffenson, B. J., 604, S100

Steigerwalt, A. G., 1240

Steimel, J., 901

Steinlage, T. A., S103

Stenger, D., S27, S38, S78, S99

Stetina, S. R., S16

Stevens, C., S81

Stevenson, J., S74

Stevenson, K. L., S34, S113

Stevenson, W. R., S74, S75

Stewart, E. L., S54, S81

Stewart, J. E., S133, S135

Stiles, C. M., S81

Stipanovic, R. D., S37, S90, 1606

Stipes, R. J., S126

Stirling, G. R., S34

St-Michel, E., S136

Stockwell, V. O., S82

Stokes, S. C., S66

Stone, A. L., S100

Stone, C. (Australia), 1524

Stone, C. L. (Maryland), S102

Stone, J. K., 121

Strausbaugh, C. A., 683, 1430, S81

Strawberry

-anthracnose: pathogen variability and genetic diversity, 219; plant extract effect on conidiation, 1285; resistance evaluation, S79; temperature and wetness duration effect, 513

_ black root rot, terbacil application, S48

— fruit rot and fruiting habit, S127

- fumigation strategy, remote sensing for evaluation, S57

-leaf scorch, photosynthetic response, S84

- marginal chlorosis, planthopper vector, in France, 644

-Phomopsis leaf blight, visual estimation reliability, 995

-root diseases, transplants, S25

-root rot, biocontrol amendments, S49

-Verticillium wilt, soil fumigant and plastic mulch effect, S33

Strawberry pallidosis virus, epidemiology and molecular characterization, S85

Street, K., S92 
Strelkov, S. E., 391

Striga hermonthica, soil suppressiveness and rhizobacteria, in Africa, S3

Stromberg, E. L., S58, S125

Struik, P. C., 666

Stuart, G., S63

Stubbs, C. S., S4

Stubbs, V., 1111

Sturbaum, A. K., 382

Styer, W., S84

Stylosanthes spp., Colletotrichum gloeosporioides, genetic diversity and centers of origin, 176

Su, Z., S28

Subbarao, K. V., 443, S47, S70, S91, S127, S131, 1572

Subbotin, S., 1093

Sudarshana, M. R., S109

Suenaga, K., 881

Sugar beet

-Cercospora leaf spot, radiometric disease evaluation, $\mathrm{S} 81$

-Pythium oligandrum, cell wall protein fraction effect, 1228

-rhizomania, remote detection, 720

Sugar, D., S35

Sugarcane, nematodes, suppressive or conducive soils, 1437

Suh, D. Y., S38

Sukno, S., S81

Sulc, R. M., S5

Sun, Z., 1354

Sundick, B. M., S82

Sundin, G. W., 1393, S106

Sunflower, downy mildew, structural and chemical changes, 1023

Sung, S. S., S68

Sunter, G., S109

Suppressive soil

-Pseudomonas spp. in Dutch take-all decline soil, antibiotic producers, 54

- sugarcane, nematode ectoparsitism, soil comparisons, 1437

Supyani, S., S36

Suslow, T. V., 727

Sutton, T. B., 381, S30, S54, S56, S70, S71

Suzuki, N., S36

Swan, B. M., S130

Swart, W. J., S9

Sweet potato

— geminiviruses, detection by PCR, S51

- viruses, RT-PCR based method for identification, S55

Sweet potato chlorotic fleck virus, characterization, S5

Swingle, P. P., S94

Switras-Meyer, S., S82

Syringa spp., disease resistance, multiple, evaluation, S63

Szabo, L. J., S82

Tabiki, T., S65

Tai, T. H., S8

Tainter, F. H., 1056

Takata, K., S65

Takehara, T., 1173

Takenaka, S., 1228

Talavera, C., 976

Talbot, B. G., S6, S132

Tally, A., S17, S34

Tan, M., 1258

Tan, X., S110

Tang, X., S108, S110

Tang, Z., S49, S67

Tanguay, P., S134

Tans-Kersten, J., S4

Tanzer, M. M., S114
Tapesia spp.

-T. acuformis, genetic structure, Washington, 650

-T. yallundae, on wheat, J genome chromosome from Thinopyum ponticum, S50

Targon, M. L. P. N., S82

Taro, A., S82, S83

Taylor, D. R., S18

Taylor, J. H., 712

Taylor, S. P., S36

Taylor, T. V., S82

Teaching

- agricultural issues and social contexts, S119

—creative options, S119

—plant pathology, extreme, S119

Teasdale, J. R., S14

Tebeest, D. O., S52

Tedford, E., S17

Tedla, T., S76

Teixeira, A. R., 1505

Teixidó, N., 436

Tellez, M. R., S68

Temple, T. N., S82

Tenney, J., S56

Tenuta, A., S6, S62

Tenuta, M., S93

Terauchi, H., 1560

Tereso, S., 278

Tertuliano, M., S42

Tetragonia expansa, Cucumber mosaic virus, systemic infection and temperature relation, 1445

Teunissen, H. A. S., 1360

Thakur, R. P., S65

Thalouarn, P., 451

Thaveechai, N., S50

Thayer, C. L., S56

Thekopsora minima

-on hemlock, temperature effect on spores, S134

-on Rhododendron, infection process, S134

Theobroma cacao, witches' broom, scanning electron microscopy, S45

Thielaviopsis basicola

-on pansy, greenhouse plug trays and disinfectants, S89

-on petunia, phosphorus stress and disease, S45

Thies, J. A., S8, S82

Thomas, C. E., S42

Thomas, C. S., S120, S121

Thomas, S. L., S83

Thomashow, L. S., 982, S20, S58, S108

Thomma, B. P. H. J., S52

Thompson, D. C., S16, S83

Thon, M., S82, S83

Thorne, J. L., S30

Thorpe, D. J., S83

Thrane, U., S83

Tian, D., S83, S84

Tilletia spp.

-T. fusca, on fescue, mating system and genetic differentiation, S89

-T. indica, teliospore survival, in soil, S10

Timmer, L. W., 1031, S63, S70

Timper, P., S20

Tiquia, S. M., 1292

Tisserat, B. H., S44

Tisserat, N., S39, S78, S121

Tjosvold, S., S28

Tobacco

-black shank, soilborne fungi effect, S31

- cyst nematode, resistance and fumigation controls, S41

- disease/stress protection, animal and plant antiapoptotic genes, S105

-Erwinia soft rot, alkaloid conversion, S80

—ethylene-insensitivity, pathogen effect, 813
- Phytophthora parasitica or phytoplasma, elicitin-induced protection, 1308

- transforming genes in, resistance to cercosporin, S35

Tobacco mild green mosaic virus, hypersensitivity on soda apple, bioherbicide, S15

Tobacco ringspot virus, in Xiphinema americanum, transmission, $\mathrm{S} 40$

Tobacco streak virus, on strawberry, old or new virus, S85

Todd, J. C., S84

Todd, T., S39, S78

Tohme, J., 88, S54

Tolin, S. A., 524, S25, S56

Toman, C., S108

Tomato

-bacterial soft rot, chlorine dioxide gas treatment, S56

-bacterial spot, bacteriocin-like substances, race 3, 1415

- Botrytis cinerea, biocontrol and dot blot technique, $\mathrm{S} 130$

-coronatine treatment, transcriptional profiling, S86

- cover crop, compost, and manure effect, S14

- early blight, compost and compost tea effect, S47

-famoxadone-based fungicides, management, S90

-Fusarium wilt: near-isogenic strain, 1360; race 3 origin in California, 1014; and Verticillium wilt, DNA array for detection, S52

-leaf curl disease, begomovirus cause, India, 1485

-Phytophthora and Pythium damping-off, coconut coir dust for, $\mathrm{S} 13$

-Pythium ultimum, nematode and collembola effect, S94

- salicylic acid and hydrogen peroxide effect, S10

Tomato bushy stunt virus, P-22-host interaction, S95

Tomato golden mosaic virus, regulation, S109

Tomato leaf curl Gujarat virus, on tomato, new in India, 1485

Tomato spotted wilt virus

-acquisition by thrips, S5

-envelope glycoproteins, oligosaccharide composition variation, S64

- epidemic in North Carolina, on potato and cabbage, $\mathrm{S} 1$

—evolutionary biology, S99

- genetic drift and selection, S84

-Impatiens necrotic spot virus, mixed infections, weeds and tobacco, S58

—integrated management, S115

-IPM practices, vegetable production effect, S115

-on peanut, transformation, nonstructural gene, S64

-on pepper, thrips resistance, 96, 1223

- protein movement, visualization using polyclonal antibody, S31

-thrips and epidemiology, S115

-thrips transmission, genetics, S79

- on tobacco, incidence factors, S19

—worldwide problem, S101

Tomato yellow leaf curl virus

-biotechnology in management, Dominican Republic, S111

- coat protein, multiple functions, S109

Tomberlin, J. K., S42

Tomita, R., 42

Tommerup, I. C., 695

Tooley, P. W., S12, S58, S84

Torrance, R. L., S77 
Torres-Pacheco, I., 270

Tory, D. R., S34

Tosa, Y., 42, S86

Tozzini, A., 136

Traquair, J. A., 323

Travis, J. W., S31, S40

Tredway, L. P., S1

Trichoderma spp., disease control, plant growth enhancement, pollution mediation, S104

$-T$. atroviride: on apple, scab resistance and chitinases, 1496; biocontrol agent, germination initiation effect on competitive capacity, 1593

$-T$. hamatum: on begonia, mildew and blight suppressed by, S37; biocontrol agent for radish bacterial leaf spot, 1292

$-T$. stromaticum, mycoparasite of cocoa witches' broom pathogen, genetics, S20

$-T$. virens: biocontrol agent, gene encoding protein, S21; biocontrol in gene pairs, S60

Trick, H., S94

Triticum spp.

-T. dicoccoides, chromosome 2A, Fusarium suppressed by, S80

$-T$. timopheevii, leaf rust resistance, transferred to wheat, 784

$-T$. triticina, on wheat, resistance transferred from Triticum timopheevii, 784

Troccoli, A., 1093

Troitsky, A. V., S9

Tronchin, G., 1023

Tronsmo, A., 1593

Trouillas, F. P., S130

Trout, T. J., S77

Troxclair, N., 1368

Trujillo, E. E., S130

Tsai, C.-W., S84

Tsang, M. M. C., S4

Tsompana, M., S84, S99

Tsror, L., S66

Tsygankova, S. V., S38

Tubajika, K. M., S84

Tudor-Nelson, S. M., 1415

Tumban, E., S84

Turechek, W. W., 458, 1587, S20, S84, S122

Turfgrass

—anthracnose: epidemiology, S112; management strategies, S112; new problems, S111; severity in mixed greens, $\mathrm{S} 86$

- disease control programs, fungicide runoff, S87

- gray leaf spot, temperature and leaf wetness duration, model, 336

- pink and gray snow mold, fungicide applications and timing, S132

Turina, M., S85

Turini, T. A., S85

Turkensteen, L. J., 382

Turner, N. E., 588

Tweddell, R. J., S85, S132

Tylenchulus semipenetrans, isothiocyanate sensitivity, laboratory assay, 747

Typhula spp.

- on cereals and grasses, DNA extraction, identification, S72

—on turf, damage assessment, S130

-on turfgrass and cereal, distribution in Wisconsin, S76

Tzanetakis, I. E., S32, S44, S85

Tzeng, K. C., S52, S53

Uddin, W., 336, S29, S86, S87, S112

Ueng, P., S124

Uhm, K.-H., 82

Ullman, D., S99, S115

Umaharan, P., 1153

Uncinula necator -on grape: boscalid and pyraclostrobin sensitivity, in New York, S91; fungicide resistance in New York, isolate shifts, S90; humidity effect, 1137; ontogenic resistance, 547, 556; weather factors, S6

- triadimefon resistance, in California, S113

Uphoff, M. D., S66

Uppalapati, S. R., S86

Upper, C. D., 1082

Usall, J., 436

Ustilago spp., taxonomy, genetic analysis, 167

- U. maydis, adapter protein essential for virulence, analysis, S46

Utkhede, R., S86, S130

Uyemoto, J. K., S130

Vacha, J. L., S73

Vaghchipawala, Z., S105

Vail, S. S., S29

Vaillancourt, L., 1471, S26, S87, S111

Vale, F. X. R., 256

Valent, B., 1452

Valinsky, L., 1006

Valiunas, D., S124

Valkou, J., S92

Vallejo, I., S14

Vanachter, A. C. R. C., S52

Van Aelst-Bouma, R., S131

Van Alfen, N., S85

Vancauwenberge, J. E., S86

Vandemark, G. J., S86

van den Bosch, F., 616, 1329

van den Bosch, T. B. M., 382

van der Sluis, I., 626

Vande Voort, J. L., S86

van Es, H. M., 1131

Vani, A., S86

van Loon, L. C., 626, 666, 813

Van Sluys, M. A., S16

Vanstone, V. A., S36

Van Tuyl, S., S24

van Wijk, K. J., S15

Vargas, J. M., S112

Vasanthakumar, A., S87

Vásquez-Siller, L. M., S87

vdM Louw, S., S9

Vedam, V., S34

Vega-Sanchez, M. E., S87

Vegetable crops, biocontrol and fertilizer relation, S6

Vélez, H., S87

Venard, C., S87

Venturia inaequalis, on apple:

-field resistance, mapping, 493

-lesion-causing efficiency, S133

Vera Cruz, C. M., S53

Verdin, E., 644

Verhalen, L. M., S7

Verkley, G. J. M., S47

Verkooijen, J., 1360

Vernière, C. J., 832

Verticillium dahliae

- on crops and weeds in New Mexico, S14

-on crucifers, molecular types, 364

-on lettuce, survival in seeds and weeds, S127

—on potato, yield loss, S27

- wilt control by residues or lignin, S20

- in wood chip mulch, infectivity, S26

Vetten, H. J., S5

Vidaver, A. K., S2

Vieira Dos Santos, C., 451

Vigna unguiculata, hypocotyl rot, bioseed treatment, organic amendments, S17

Viji, G., 336, S29, S86, S87

Vikram, A., S72

Vikram, B. A., S55
Vilgalys, R. J., 610

Viñas, I., 436

Vincelli, P., 891, S87

Vinyard, B. T., S14

Viret, O., 316

Viruses

-begomoviruses, Macroptilium lathyroides and common bean, 774

_-gene silencing, resistance signaling, S110

- mosaics on brome, tobacco, alfalfa, and panicum, Tomato bushy stunt, ribosome-inactivating proteins, 588

- on olive, detection with reverse transcriptionPCR, 286

—using PCR group test primers, S34

-resistant durability, analysis, 941

-RNA, intraspecific recombination, methods, S27

-spherical ssRNA, phylogenetic analysis, S63

-tospoviruses: diversity, management and vectors, S115; emerging in USA, S115

Visker, M. H. P. W., 666

Vivanco, J. M., 588

Voisin, R., 160

von Broembsen, S. L., S68

Vossbrinck, C. R., S23, S133

Vovlas, N., 1093

Vujanovic, V., S132

Vuong, T. D., S17, S88

Wach, M. J., S44

Walcott, R. R., 528, S60, S88

Waldvogel, J. A., S119

Walgenbach, J., S115

Walker, N. R., S19, S62

Walkinshaw, C. H., S35, S68, S88

Walla, J. A., 1037, S88

Wallis, C., S100

Wallwork, H., S2

Wan, A., S10, S88

Wan, H. W., S52

Wan, J., S110

Wang, C., 1258

Wang, G.-L., S40, S41

Wang, H., S95

Wang, J., S97

Wang, K.-H., S88

Wang, N., S88

Wang, X. (China), 160

Wang, X. (North Carolina), S88

Wang, X.(Washington), S89

Wang, X.-J. (Virginia), S89

Wang, Y. H., S31

Wang, Z., S41

Wanner, L. A., S89

Warfield, C., S89, S122

Warren, K., S77, S108

Watermelon

-Acidovorax avenae on, seed infestation and blossom role, 528

-bacterial fruit blotch: biocontrol seed treatment, S60; control with plant defense activator, S37; detection seeds, S72

- gummy stem blight, azoxystrobin resistance, S113

-wilt, resistance quantification, S95

Watrin, C., S1

Wayadande, A., S64, S89

Webb, S. E., S89

Webber, J. F., S118

Webster, T. M., S58

Wedge, D. E., 46

Weeds, P. L., 176

Weeks, J. R., S32

Weestwood, J., S32

Wegulo, S. N., 513, 1285, S46 
Weiland, G. E., S89

Welacky, T., S62

Welham, S. J., 657

Weller, D. M., 54, 982, S20, S58

Wen, G., 1258

Wen, K., S136

Wendel, L., S84

Wenner, N. G., S54, S81

West, D. R., S11

West, L., S89

Westphal, A., 1182

Weyant, R., 1240

Wharton, P. S., S90, S111

Wheat

-common bunt, resistance, crown and tissue comparison, S54

-cross with foxtail millet, Magnaporthe grisea, 42

- crown rot complex, management in Pacific Northwest, S125

-eyespot: genetic structure of pathogen population, Washington, 650; infection and thermal time, S10, S88

-Fusarium head blight, biocontrol agent, S17; biocontrol by Lysobacter enzymogenes, S93; epidemics and risk assessment models, 428; forecasting in Ohio, S53; incidence-severity relation, S23; multienvironment trial, inoculation comparison for resistance, 1068; previous crop effect, S75; resistance gene in substitution lines, $\mathrm{S} 80$

-Fusarium-infected kernels, deoxynivalenol and irrigation relation, $\mathrm{S} 19$

- Gibberella zeae, epidemic populations in Kansas and North Dakota, 874

-head blight: Fusarium spp., diversity, S3; species populations, S23; trait loci and pathogenicity, S19

-Karnal bunt, cultivar reaction, S29

-leaf and stripe rusts: durable resistance in CIMMYT, S112; resistence, gene markers, 881; resistance, molecular markers, 153

-leaf rust: resistance genes in Minnesota, S67; resistance transferred from Triticum timopheevii, 784

- powdery mildew, silicon effect, cytology, 402

- Pythium oligandrum, cell wall protein fraction effect, 1228

-Pythium spp. communities, in Washington, 867

-root diseases and direct seeding, S77

-root-lesion nematode, yield effect, S129

-rust resistance, wild relatives, $\mathrm{S} 92$

- Septoria leaf blotch and Fusarium head blight, tan spot, crop history, S60

-Septoria tritici: epidemic, weather models, 1329; leaf blotch, resistance, genetic mapping, S21; resistance gene, mapping, 1158

- soilborne pathogens, survey in Idaho, S81

- speckled snow mold, temperature and soil matric potential effect, S65

- stem and leaf rust, detection with PCR assays, S82

-stripe rust: control in Pacific Northwest, S16; resistant genes in Chile, S56

- tan spot: and leaf rust, management, S18; new races and one-to-one relation, diversity, 391; Ptr ToxA, host sensitivity, 397

Wheat soilborne mosaic virus

-resistance, strategy and analysis, S13

-soil environment effect on transmission, 1131

Wheat spindle streak mosaic virus, alternate hosts, ciliated protozoans, S13

Wheat streak mosaic virus

-coat protein gene for transformation, silenced transgenes for reactivation, S52

—population genetics and evolution, S99 —variation in isolates, S78

Wheeler, M. H., S90, 1606

Wheeler, T. A., S48

White, D. G., S13, S46

White, L. A., 1240

Whittaker, R. G., S79

Wick, R. L., S134, S135

Wickizer, S. L., S40

Wicklow, D. T., S59

Widstrom, N., S42

Wigley, P. D., S11

Wilcox, W. F., 547, 1137, S28, S44, S60, S82, S90, S91

Wilhelm, K. P., S75

Wilk, D., S85

Wilke, A., S64

Wilkinson, H. T., S27

William, H. M., 881

William, M., 153, S112

Williams, R., S58, S78, S90

Willie, K., S84

Wilson, A. D., S90

Wilson, C. L., 344, 349

Wilson, C. R., 752, S71

Wilson, D. M., S42

Wilson, J. P., S42, S90

Wilson, L. L., S65

Wilson, M. A., S81

Windass, J., S67

Windels, C. E., S90

Windom, G. E., S127

Wing, R., S40

Winter, S., S5

Wintermantel, W. M., S85, S101

Winton, L. M., 121

Wipf-Scheibel, C., 1478

Wise, R. P., S32

Wisler, G. C., S101

Wisniewski, M., 344

Witherell, R. A., S67

Wolf, H. C., S90

Wolf, T. K., S7

Woloshuk, C. P., S9, S97

Wong, F. P., S90, S91, S111, S114

Wong, M.-Y., S91

Wood

- pathogens imported on, movement pathways, S119

— pests transported by, mitigation, S119

- products, phytosanitary measures, international, S119

Wood, B. W., S66, S73

Wood chip mulch, tree pathogen survival in, S47

Wood, D. A., S16

Wood decay, mycosymbionts, wood wasps, S90

Wood importation, exotic fungal pathogen introduction, S118

Wood, D. W., S108

Woods, S., 167

Woody, S. T., S91

Workneh, F., 901

Wu, B. M., S70, S91, S131, 1572

Wu, C. X., 959, S57

Wubben, M. J. E., S91

Wyenandt, C. A., S91

Xanthomonas spp.

-X. arboricola, on prune, putative protein, ATPbinding system, S68

$-X$. axonopodis: on citrus, pathogenicity, virulence, and profiles, S5; on citrus, phytosanitary measures, standards, S12; on citrus, symptoms in tissues, 832; on citrus, wind-blown spray, sample techniques, S70; genetic variation, S21

-X. campestris: on bean, races in Nicaragua, Costa Rica, and Puerto Rico, S93; on cotton, cover photo, October; on cotton, phyllosphre inoculation technique, 1204; on lettuce, genetic diversity in bacteria, 596; on lettuce, strain diversity, 64; on onion, resistance screening, S29; on pepper, bactericide evaluation, S21; on pepper, systemic resistance, defense-related genes and oxidative burst, S38; on pulse and weeds, population dynamics, $\mathrm{S} 29$; on tomato, new races and mutagenesis, S62; on tomato, race 3, bacteriocins, 1415; on zinnia, cercosporin degradation, regulators and enzymes, $\mathrm{S} 82$

-X. citri: on citrus, PCR for detection, in Thailand, S50

-X. cucurbitae, on pumpkin, seed treatment, $\mathrm{S} 134$

-X. oryzae: genetic variation detection, AFLP fingerprinting, S43; on rice, new race in Korea, S66; on rice, resistance and gene mapping, 1258; on rice, resistance inheritance, 147; on rice, strain antagonistic interactions, 705; on rice, variation and resistant gene, $\mathrm{S} 53$

$-X$. translucens, on cereals, DNA polymorphism, Russia, S38

Xiao, C. L., S92

Xiphinema spp., on grape, ribosomal genes and specific primers, identification by, 160

$\mathrm{Xu}, \mathrm{H} ., \mathrm{S} 92$

$\mathrm{Xu}, \mathrm{R} ., 1407$

Xu, X. (China), 1258

Xu, X. M. (U.K.), S92

Xue, A. G., 329

Xylella fastidiosa

-biofilm formation and colony size, nutrition effect, S50

-on citrus: geographic genetic structure, Brazil, 28; sharpshooter transmission, S19

- fimbriae produced by, cover photo, June

-on grape: detection using xylem fluid, S8; exopolysaccharide production, S74; fimbrial genes, site-directed, 675; genomic characterization, S16; inoculation date effect, 244; sharpshooter feeding behavior, S6

- on grape and citrus, detection methods, S25

- hydrophobicity and biofilm, S50

- mutants, triparental matings, S51

-on plum, coffee, and citrus, colonization and symptom comparison, $\mathrm{S} 4$

-on sweet orange, fruit, seeds, and transmission to seedlings, 953

-on sycamore, temperature effect, S34

-taxonomy, S76

- on tobacco, colonization patterns, S4

- transformation, RSF1010 derivative plasmids, S31

Yahyaoui, A. H., 391, S92

Yamada, T., S102

Yamagishi, N., 1560

Yamamoto, H., 768

Yan, F., S6

Yandoc, C., S75, S92

Yang, J. (Canada), S45

Yang, J.-S. (China), 112

Yang, M. S., S45, S69

Yang, R.-C., 633

Yang, X. B., 758, 901, S51, S65, S66, S71, S92, S103, S104

Yang, Y., S60, S73, S95

Yao, J., S4, S93

Yap, M.-N., S93

Yates, D., S3

Ye, T. Z., 633

Yee, D., 1533

Yeh, F. C., 633

Yeh, S.-D., 112 
Yin, B., 1006

Ying, Z., S71

Yoder, K. S., S114

Yorinori, J. T., S103

Yoshimura, M. A., S56

Young, D. D., S67

Young, I. M., 1111

Ypema, H., S54

Ytterberg, A. J., S15

Yu, Q., 1124

Yu, T.-A., 112

Yuan, C. Y., S93

Yuen, G. Y., 1103, S51, S93

Yurgel, S., S77, S108

Zaffarano, P. L., S53

Zala, M., S53

Zambino, P. J., S33, S73, S74

Zanzot, J. W., S93

Zapata, M., S75, S93
Zarnoch, S. J., S68

Zasada, I. A., 747, S93

Zavriev, S. K., S34

Zee, F. T., 1124, S43

Zeigler, R., S54, S110, S121

Zeller, K. A., 853, 874, S39, S93

Zeller, W., S2

Zemetra, R. S., S52

Zettler, F. W., S119

Zhang, C., S94

Zhang, D., 1258, S94

Zhang, H., S33

Zhang, J. (Ohio), 64

Zhang, J. X. (Florida), S94

Zhang, Q., 1240, S94

Zhang, S., S94

Zhang, W., S94

Zhang, Y., S94

Zhao, B., S94

Zhao, T., S95
Zhao, Y., S32, S49, S95

Zheng, C., S95

Zheng, Q., S71

Zhexembekova, M., S95

Zhong, S., 604

Zhou, B., S40

Zhou, X. (Arkansas), S60, S95

Zhou, X. G. (Maryland), S95

Zhu, S., 860

Zhu, X. Q., S31

Zidack, N. K., S7, S117

Ziems, A. D., S95

Zilberstaine, M., 356, 931

Zingiber officinale, bacterial wilt, molecular diversity in Hawaii, 1124

Zitter, T. A., S27, S134

Zreik, L., 644

Zucchini yellow mosaic virus, symptom severity and relative fitness loss, 1478

zum Felde, A., S96 